\title{
الابعاد الفكرية والبنائية للخزف الاوربي المعاصر
}

\section{Enas_Albshara@yahoo.com أ.م.د. إيناس مالك عبد الله جامعة بابل/ كلية الفنون الجميلة}

ملخص البحث

تتاول البحث الحالي (الابعاد الفكرية والبنائية للخزف الاوربي المعاصر) وقد احتوى هذا البحث على أربعة فصول, تضمن الفصل الاول الاطار المنهجي للبحث والذي تمثل بمشكله البحث, التي تتاولت رغبة الخزاف الاوربي المعاصر في ايجاد صورة بصرية جديدة تحمل ابعاد فكرية وبنائية ذات قيمة جمالية وفنية عالية للمنجز الخزفي كما واحتوى هدف البحث (تعرف الابعاد الفكرية والبنائية للخزف الاوربي المعاصر) أما حدود البحث فقد اقتصرت على دراسة الاعمال الخزفية المنجزة في أوربا (المانيا, ايطاليا, فرنسا, بريطانيا, سويسر) للمدة (1990-2000) لتمازج الابعاد الفكرية والبنائية للخزافين الاوربيين المعاصرين مع مدارس الإسئ الفن الحديث, باعتماد المنهج الوصفي - طريقة التحليل - في تحليل عينه البحث.

اما الفصل الثاني فقد تضمن مبحثين, أشتمل البحث الاول الاطار النظري والدراسات السابقة, وأهم المؤشرات التي اسفر عنها

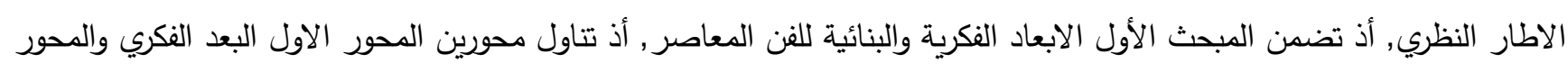

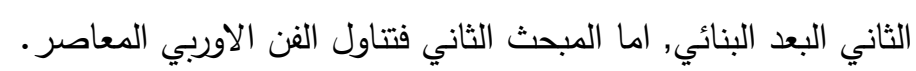
وتضمن الفصل الثالث اجراءات البحث التي احتوت مجتمع البحث وعينته ومنهج البحث وتحليل العينة البالغة (5) أعمال خزفية, وقد اشتمل الفصل الرابع على نتائج البحث والاستتتاجات والتوصيات والمقترحات, ومن جملة النتائج التي توصلت اليها الباحثة ما يأتي:-

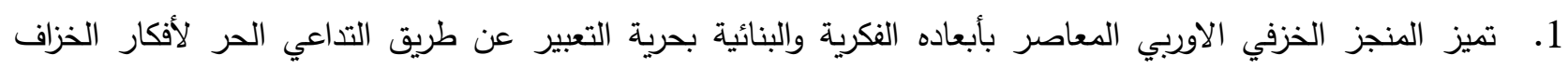
والانسياق نحو حرية الفعل.

2. اقترب الهنجز الخزفي الاوربي بأثكاله التجريدية الهندسية من الهنحى التكعيبي من حيث (الفكرة والبناء الثكلي), حيث الدفارقة القصدية للواقع والانفصال عنه.

\section{Abstract}

The current research discusses (Intellectual and structural dimensions of European contemporary pottery) and it contains four chapters, the first chapter includes the methodological framework of the research which represents the problem of the research that tackled the intent of the contemporary European potter to find a new visual image that carries Intellectual and structural dimensions with a high aesthetic and artistic value for the pottery work. The research also contains the aim of the research (identifying the Intellectual and structural dimensions of European contemporary pottery). The research limits were restricted to studying pottery works in Europe (Germany, Italy, France, Great Britain and Switzerland) for the period (1990-2000) because of the intermixing of the Intellectual and structural dimensions of European contemporary potters with the modern art schools. the researcher used the descriptive approach -analysis method-in analyzing the research sample.

The second chapter contains two topics. The first research includes the theoretical framework, previous studies and the most important indicators resulted from the theoretical framework. The first topic of the second chapter includes the Intellectual and structural dimensions of contemporary art as this topic tackled two aspects: the first one is the Intellectual aspect and the second one is the structural aspect. The second topic discusses the European contemporary art.

The third chapter contains the research procedures that included the research community, research sample and the analysis of the sample which is amounting to (5) pottery works. The fourth chapter includes research results, conclusions, recommendations and suggestions; the most prominent results reached by the researcher are as follows:-

1. The European contemporary pottery work with its Intellectual and structural dimensions is distinguished by the freedom of expression through the free association of the potter's thoughts and moving towards the freedom of conduct.

2. The European contemporary pottery work with its abstract geometric shapes is close to the cubical approach in terms of (idea and modal construction), at which the purposive paradox of reality and separation from it. 
ان الفن في مفهومه العام يعطي صورة حية عن حياة الثعوب ويعبر عن أفكارهم وتقاليدهم وعاداتهم, فهو (الفن) دائم الخوض في حقول المعرفة البرهانية أو الجدلية لإنتاج التعددية والاختلاف, متخذاً اتجاهات تواصلية فكرية متعددة الاهداف والغايات, والفنان بدوره يمتلك القدرة في التعبير عن الأفكار وتجسيد المشاعر والتطلعات الإنسانية العميقة. ويعد الفن شكل من اشكال النتاج الفكري الذي يدعو الى افتراض ابعاد فكرية وبنائية تثكل الأشياء والظواهر , بصورة قد تتجاوز

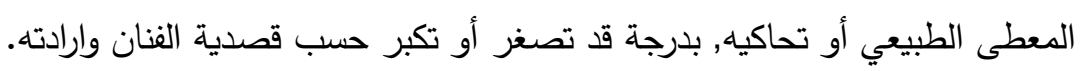

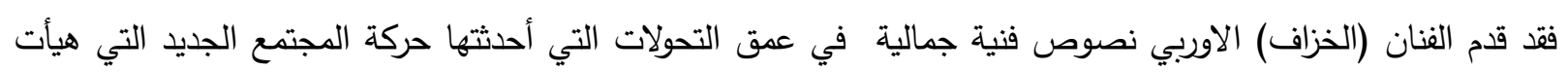

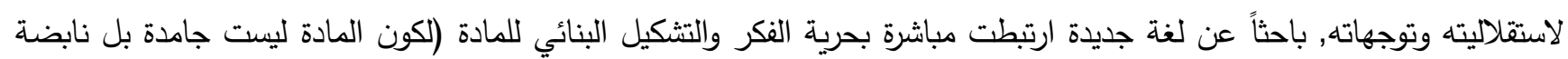

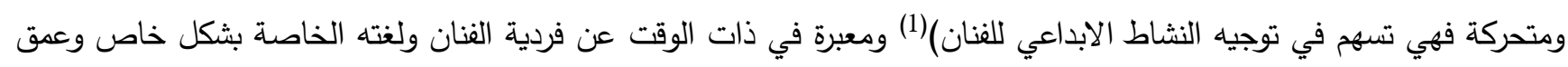

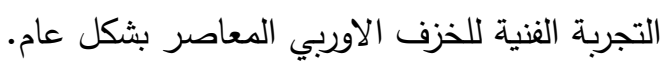

فالفن عموماً وفن الخزف الأوربي خصوصا وجوب تحديد أبعاده الفكرية والبنائية, وتأسيس أرضية صلبة يمكن من خلالها ان

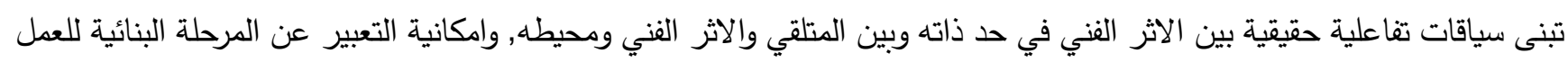

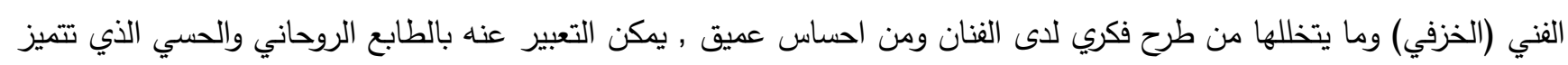
به أي تجربة فنية جمالية. وعليه جاء البحث لدراسة (الأبعاد الفكرية والبنائية للخزف الاوربي المعاصر , فالخزاف الاوربي الان لديه الرغبة في المغايرة والخروج عن المألوف, محاولاً الاقتراب من عالم الجمال اللامحدود في نتاجه الخزفي, ففن الخزف أصبح أكثر اتساعاً وتتوعاً وتمازجاً واختلاطاً مع باقي اجناس الفن وأضحى كل شيء يمكن أن يكون عملاً فنياً, وهذا يتطلب وجود ثقافة تثكيلية تمكن المتلقي من ملامسة الابعاد الموضوعية للعمل الفني سواء من الناحية البصرية أو الفكرية والبنائية والفلسفية. وهذا مادفع الباحثة الى تناول هذا الموضوع في فن الخزف الاوربي المعاصر بوصفه موضوعاً يستحق الدراسة ولم يتم دراسته سابقاً (حسب علم الباحثة) بهذه الكيفية في (الخزف الاوربي المعاصر ) مما ولد مساحة مهمة للبحث وسط الثغرات المعرفية والفكرية والبنائية

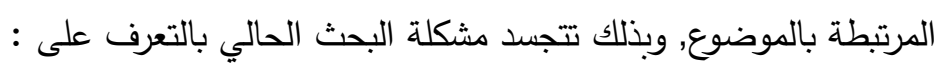

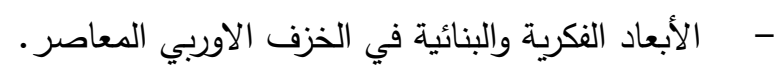
كما تمثلت أهمية البحث بما يلي: 1. رفد المكتبة العراقية والعربية بجهد علمي خدمة للمهتمين في مجال الدراسات النقدية والفنية المعاصرة.

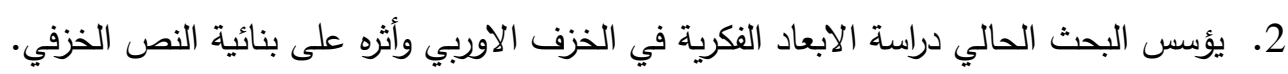

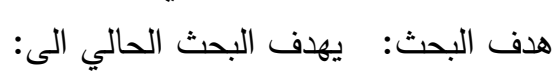
- - تعرف الابعاد الفكرية والبنائية للخزف الاوربي المعاصر . حدود البحث: 1. الحدود الموضوعية: الاعمال الخزفي المنجزة في أوربا.

2. الحدود المكانية: الاعمال الخزفية المنجزة في أوربا ( المانيا , ايطاليا , فرنسا , بريطانيا , سويسرا )

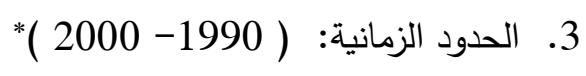


أ. لغةً: البُعد ضد القرب وقد (بَعُد) بالضم بُعداً فهو (بعيد) أي (متباعد) و (أبعده) غيره و (باعده) و (بعده تبعيداً)(1). ب. اصطلاحاً: عرف ارسطو (البُعْد) على انه الحكم الذي يصدر عن العلم بالمعلوم, من حيث أن المعلوم متأخر بالطبع عن علته في

مقابلة (قبلي)(2).

ثانياً: الفكر (Thought)

أ. لغة: فكر يفكرُ : فكراً وفكراً في الثيء: أعمل ليفكر والعقل فيه ليتوصل الى حله أو ادراكه(3).

ب. اصطلاحاً: الفكرة: أسمى صور العمل الذهني بما فيه من فئ تحليل وتنسيق(4). فالتفكير عملية معرفة تتم عن طريق المفاهيم أو التصورات, لأننا في التفكير انما نقيم علاقة مابين مفهوم أو تصور مابعده

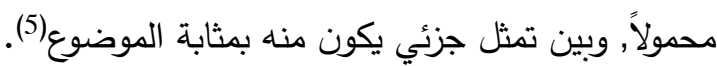

(Structure) ثالثاً: البنائية

أ. لغةً: في معجم اكسفورد وردت البنائية بأنها: طريقة البناء , التجميع أو التركيب, التظيم (6). ب. اصطلاحاً: البنية, مفهوم تجريدي, لاخضاع الاشكال الى طرق استيعابها, والبنية نظام تحويلي, يشتمل على قوانين, ويغتتي عبر ورئر

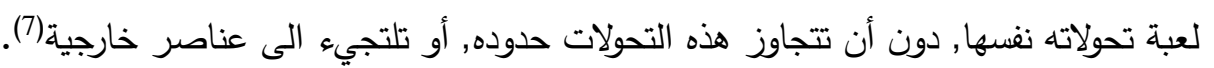

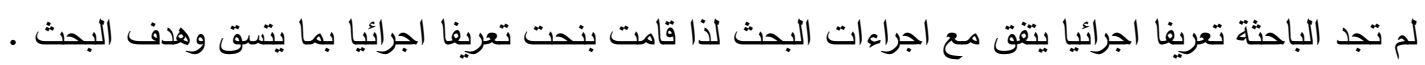
إجرائياً: البعد الفكري: هو تصور ذهني يعكس العالم الموضوعي من مفاهيم ونظريات وأحكام انعكاساً وسيطاً للواقع, مها أثر على طبيعة التكوين الفني الجمالي للعمل الخزفي.

البعد البنائي: هو التوظيف البنائي للعناصر ووسائل تتظيمها الجمالي تبعاً لتحولات البنى الاسلوبية للخزاف الاوربي المعاصر. المبحث الأول : الابعاد الفكرية والبنائية للفن المعاصر

أ. البعد الفكري: يعد تاريخ الفكر الفلسفي الحديث هو الصورة الواقعة المعالم لمجهود الفكر الانساني عبر تاريخ الفلسفة الطويل, فقد

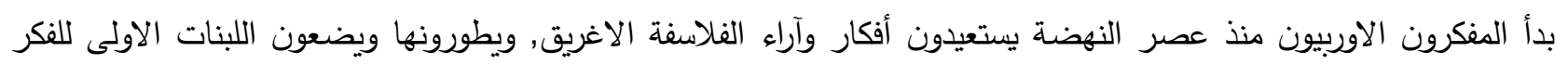

الفلسفي الحديث, ماساعد على تطوير مذاهب فكرية وفلسفية جديدة*, أدت الى تغير شكل التفكير والفلسفي لكل حقبة زمنية. فالحداثة حاولت أن تحقق فكرة الانسجام والتداخل مابين المعطيات الفنية والجمالية والفلسفية على حد سواء , فهي (الحداثة) تقوم

على مفاهيم أساسية ثلاثة:

1. الذاتية: وهي أول الدفاهيم التي شكلت قاعدة الحداثة في مجال الفلسفة, فالفنان الحديث يدرك نفسه كذات مستقلة, وهذه الفلسفة

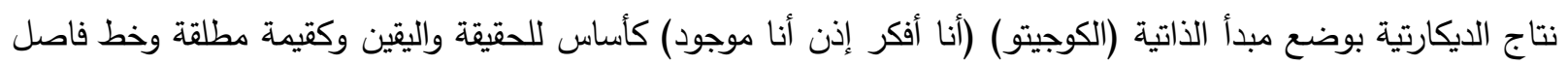
بين عالم الالهة وعالم الانسان الذي هو مركز الكون (8).

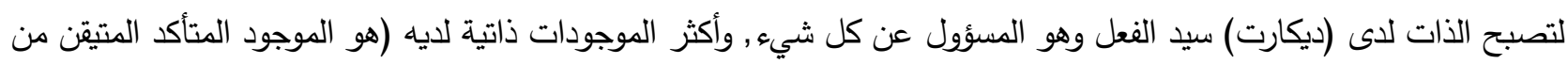

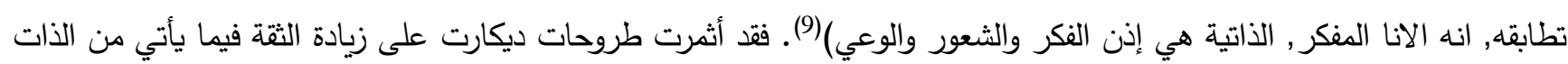
الحرة من أفكار وابداعات تجسد ارادتها في الحياة .

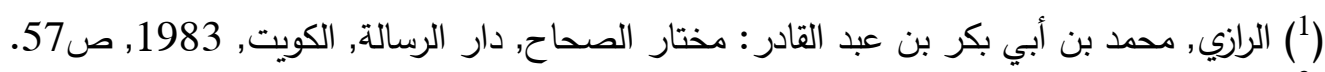

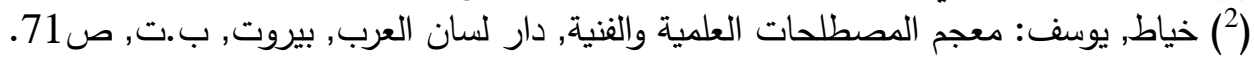

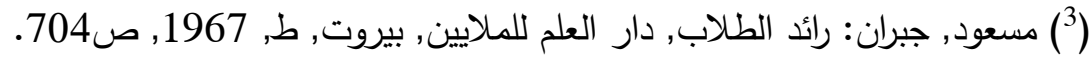

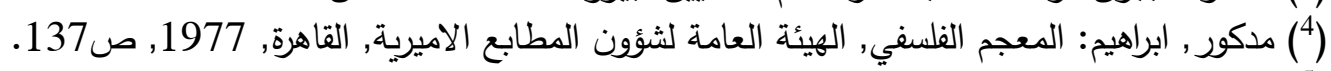

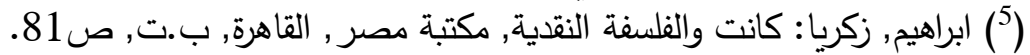

(6) Hornby, A.S.: Oxford Dictionary, Oxford University press, London, 1975, P.874.

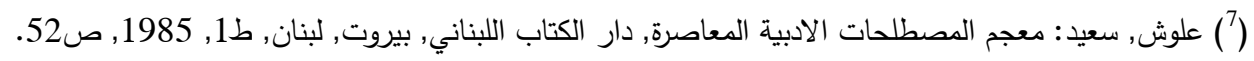

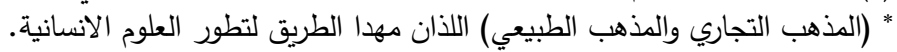

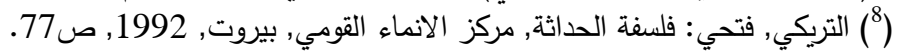
(9) العالي, عبد الَّلام بنعبد: أسس الفكر الفلسفي المعاصر - مجاوزة الميتافيزيقيا, دار توبقال للنشر , الدار البيضاء, المغرب, ط1, 1991, ص108. 
2. العقلانية: يعد (لاينتز) مؤسس الحداثة الفلسفية على مبدأ العقلانية بمعنى ان لكل شيء سبب معقول, فالفنان يتحول من متأمل للكون الى منقب اسراره حتى فتحت أمامه أبواب العلم الحديث.

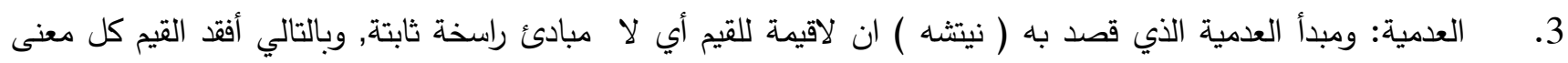
وحقيقة, وتبريره لذلك هو ميل الفلسفة والفن الحديث الى البحث عن قيم جديدة تعوض بها القيم المنهارة(1).

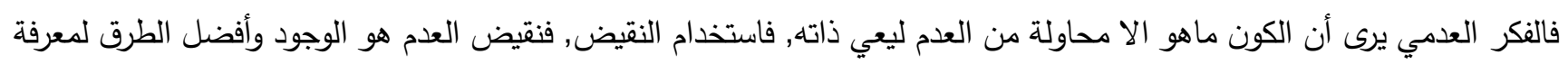
الثيء هي معرفة نقيضه. ومهدت الحداثة الفلسفية الطريق لظهور ( عمانوئيل كانت) على المسرح الفكري وتطويره للفلسفية النقدية, بحيث أصبح النقد عنده صيرورة معرفية وفعالية فكرية. فالبعد الفكري لاى كانت يؤكد على أن استخدام العقل وحده دون التجربة لايقود الى معرفة دقيقة بل يقود الى الاوهام, اما استخدام

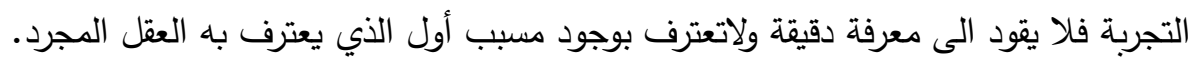

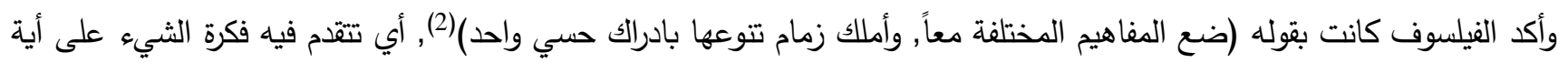
محاولة لتسجيل مظهره. وشكلت الطروحات الهيكلية نقطة تحول في الجدل الروحي في الفكر الفلسفي المثالي, اذ جعل من الفلسفة المثالية نتاجاً للعقل التأملي(3). يرى هيكل في الفن (انزال فكرة في مادة وتثكيلها على مثالها)(4). مؤكداً ان وظيفة الفن في التعبير عن المثال وتكثف الحثئ الحقيائق المطلقة

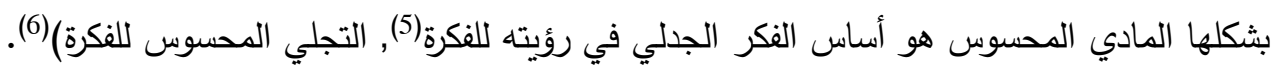

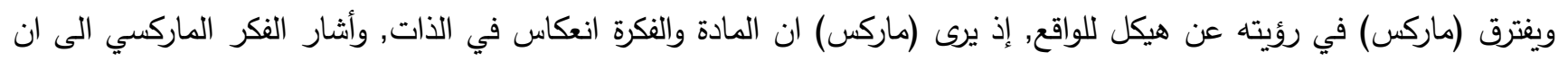

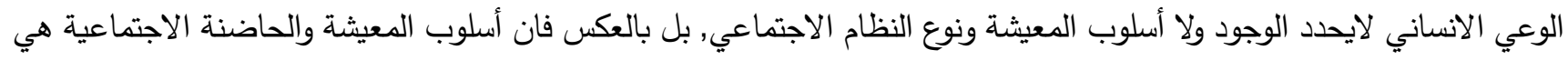
التي تحدد الوعي, وبتعبير أدق ليس التفكير هو الذي يحدد نمط الوجود, بل الوجود هو الذي يحدد نمط التتكير (7).

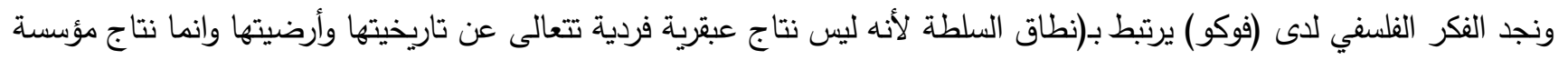

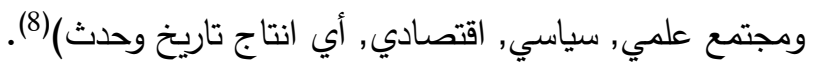
ويرى (دولوز) ان أي فكرة تقام أصلاً على جملة من العلاقات التفاضلية الاختلافية لا التماثلية - فالأفكار ماهي الانست من من التعدد

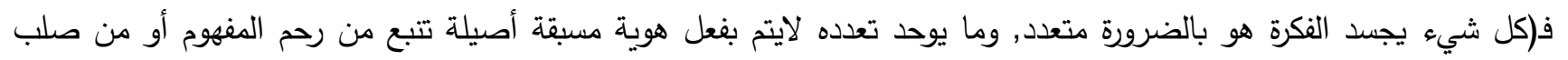

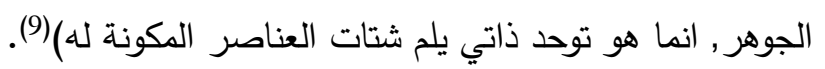
وكان البعد الفكري لدى (دريدا) يهتم بنقد التمركز حول العقل وفكرة الحضور فهو يطمع الى تنكيك كل المراكز الدلالية وبؤر المعاني

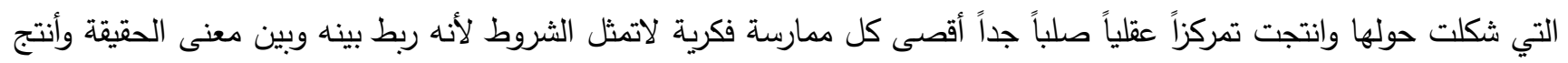

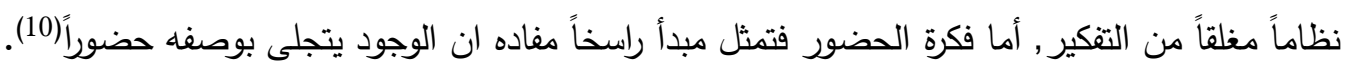
ويقترب الفكر الفلسفي لدى (ليوتار) من عدمه ينتشه فيشير الى (ان لاوجود للمعاصر في عصر بدون تحطيم المعتقد وبدون اكتثاف افتقاد الواقع جنباً الى جنب مع ابتكار واقع آخر)(11).

(1) الثيخ, الطائري: مقاربات في الحداثة ومابعد الحداثة, دار الطليعة للطباعة والنشر , بيروت, ب.ت.

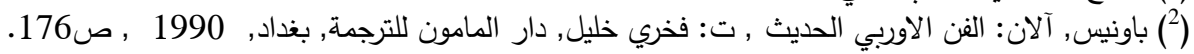

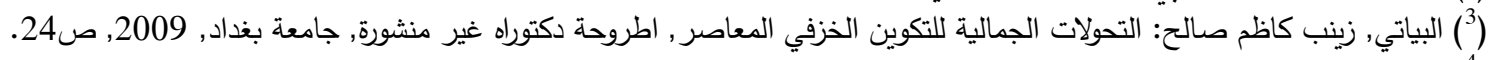

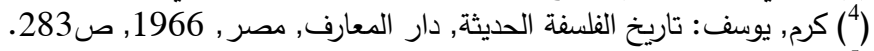

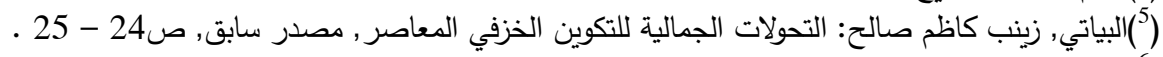

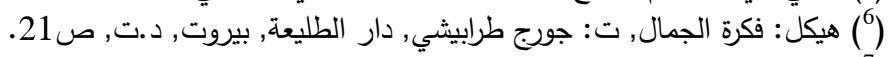

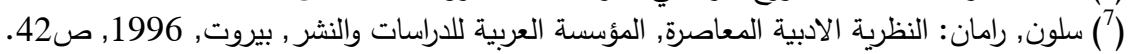

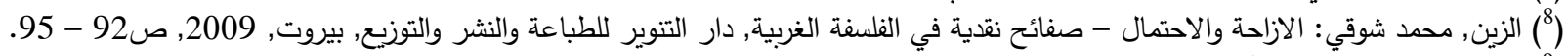

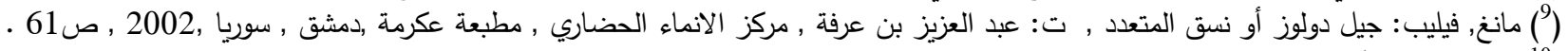

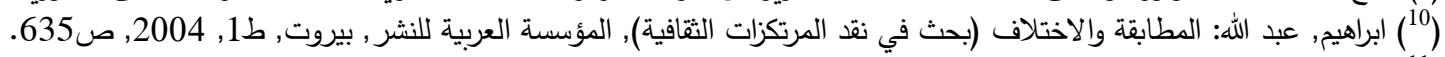

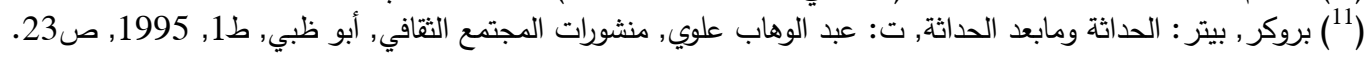


وتقوم فكرة (ليوتار) لكي نعرف معنى كلمة أو عبارة لابد من أن نعرف طريقة استخدامها وكيف يؤدي دورها في التفاعل بين الناس يصدر أحكاماً وتعبيرات معرفية فان هناك أنواع مختلفة كثيرة من التعبيرات تخرج عن نطاق العلم مثل التعبيرات الادائية(1).

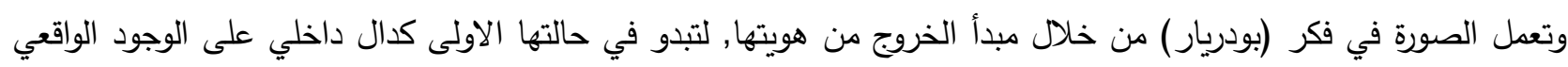

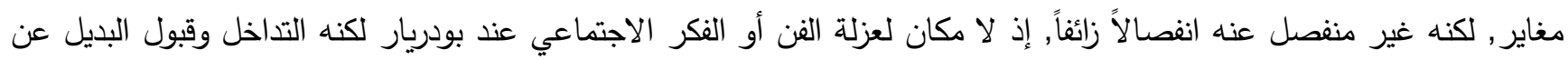
الأصل من خلال التثبيهات والمحاكاة في التكوين الوجودي والمدلول المعرفي معاً. فأصبحت الصورة أكثر واقعية من الواقع , متجاوزين الفترة التي كان فيها الانتاج (النسخ) والتمثيل يمثلان الجوانب الاكثر أهمية

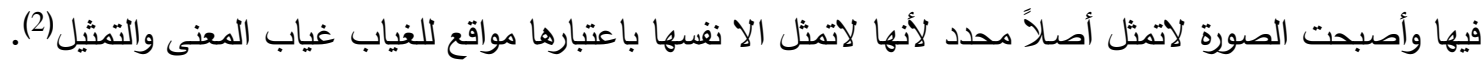
وبناءاً على ماتقدم نجد هناك الكثير من الاختلاف والتوافق في الابعاد الفكرية ووجهات النظر لدى النقاد والفلاسفة, الا انه يمكن لألفابل

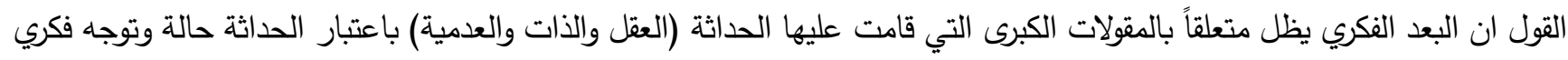

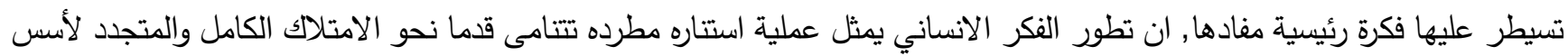
الفكر وقواعده. ب. البعد البنائي:

يعد الفن دائرة معرفية واسعة تتأسس محاورها من ظواهر فكرية وتقنية متتوعة, تتحرك بنظام علاقات لايخلو من ظاهرة جدلية لينفتح وفق آليات الاستعارة والترحيل والاستبدال, وبفعل التحليل والتركيب على آفاق جديدة ومتتوعة من الأداءات البنائية وآفاقها الفكرية ونظراً

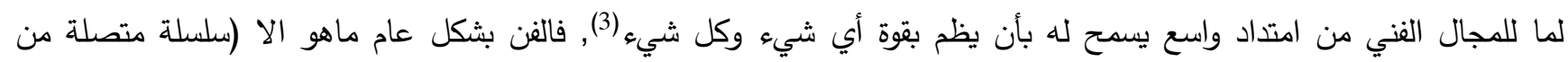
المتراكمات البنائية على مستوى البناء المادي (التقني) أو الاتجاهات الاسلوبية أو الاستعارات والتحولات الثكلية داخل الوسائط الناقلة وعلى مستوى الوعي الرؤيوي الذي يقود التجربة الفنية ويوجه خطوطها.)(4). فالمنجز الفني (الخزفي خصوصاً) تكوين ذو انشاء شامل لعموم الاداءات الفكرية والتقنية والتي يحقق لوجودها دائرة جمالية وهيكلية مترابطة من العلاقات التي لايمكن للعمل الفني أن يكون الا من خلال ترابطها وتفاعلاتها الجدلية. ويتحرك مفهوم التقنية منذ بدايات الفن الحديث مع التقدم العلمي والتكنولوجي والصناعي في مجال الخامات والادوات التي وسعت من من القدرات الابداعية للفنان والتعرف على خاماته, حتى أصبحت هذه التقنيات قدرات وخيارات تثكيلية مفتوحة تصب لصالح صورة المنجز الفني وأصبح من الطبيعي عند الحديث عن شكل المنجز الفني يرد بطريقة مؤثرة بفعل التقنية بدءاً من اختيار الفنان للخامة والقيام بالعمليات الادائية التنفيذية, مع استمرار عملية تفاعل حواسه وقدراته التشكيلية مع الخامة(5), (مرحلة الاستبصار الجمالي لتحقيق الفكرة الابداعية)(6). أن فنون الحداثة ومابعدها ماهي الا ثورة جمالية على مجمل بنية تاريخ الفن التشكيلي وعلاقاته اللونية والبنائية التقليدية القائمة وحتى على الموضوعات والأفكار المحملة فيه تمهيداً للرفض الاجتماعي والانساني (7).

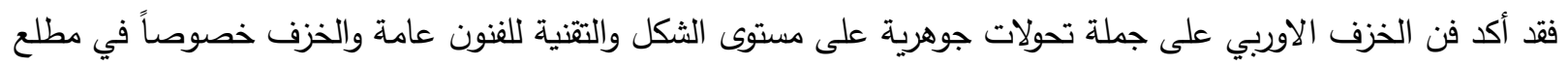
ومنتصف القرن العشرين بعد أن تم تجاوز المألوف من الأشكال الطبيعية واستتساخها في الفنون التثبيهية ابتداءاً بمراحل التبسيط

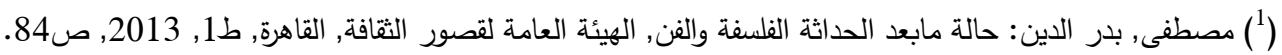

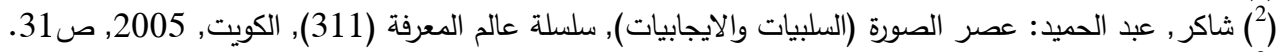

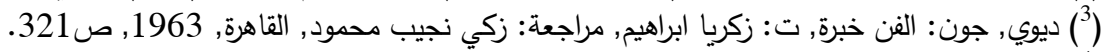

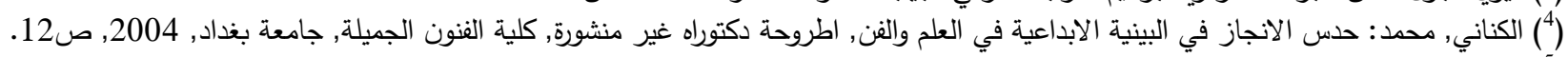
(5) غانم, فاروق عبد الكاظم: تناسق التقنية والوعي الجمالّي في اظهار الثكل الخزئ الثزفي, اطروحة دكتوراه غير منشورة, جامعة بغداد, كلية الفنون الجميلة, 2013,

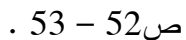

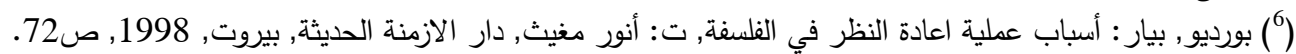

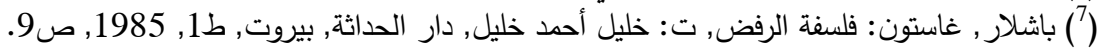


والاختزال وللمغادرة لتلك الحرفية الدقيقة بفعل تحول ضاغط الفكر العام الى الخاص والتقدم العلمي والتكنولوجي وشيوع ذاتية الفنان وسيادتها في التعبير الفني(1).

فالبنية الثكلية تعد من أهم البناءات المكونة للمنجز الفني من حيث انها تصوغ المظهر الخارجي للمنجز الفني وتحدد أبعاده

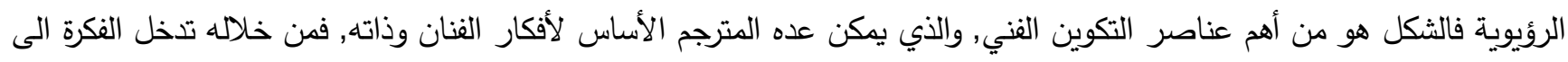

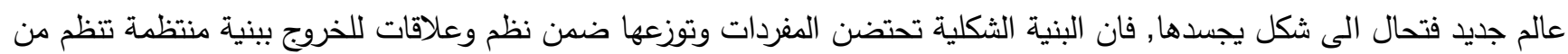

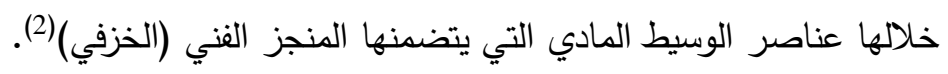
فالفن بطبيعته ميال الى الخيالي أو الافتراضي كجزء من خصوصيته ووظيفته, فالفنان التكعيبي يبحث عن نوع من الخيال الرافض للواقع , والمستقل عن كل ماهو واقعي وصولاً الى نوع من التجديد العقلي كحقيقة متعالية تتلاشى من خلالها علاقة الثكل

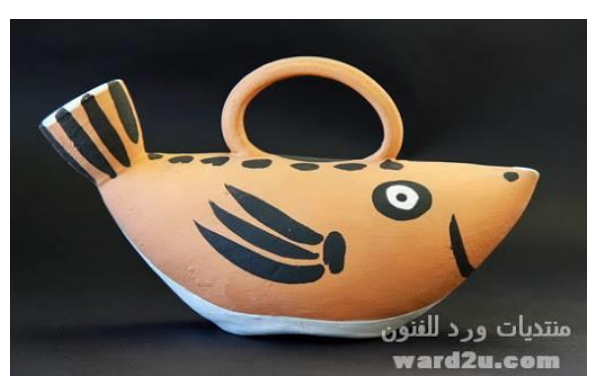
ward2u.com

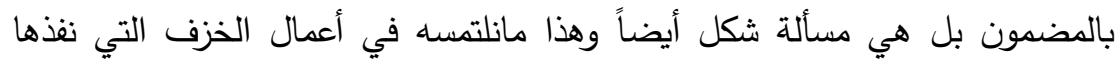

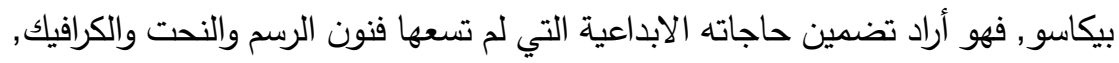

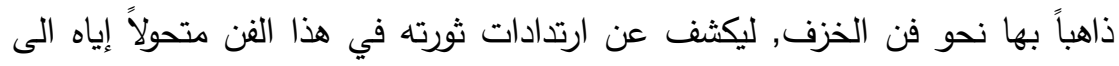

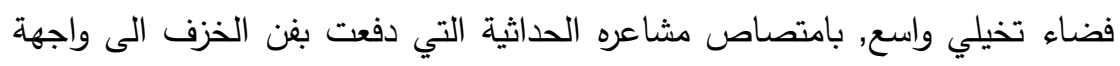
الأجناس الفنية, إذ يتضح فيها التراكيب المرتجلة والأشكال غير المهندمة والخطوط دئناءون

شكل (1) المتراسلة مع المشاعر الانية(3) شكل (1). وظهر الفن التجريدي عندما انفصل الفنان بذاتيته عن الموضوع الخارجي وابراز التصميم البنائي واعتماده عناصر الثكل وفق مفاهيم شمولية كونية كالاتزان والتجانس والتتاغم والايقاع(4), كما عمد (كاندنسكي) لحل مشكلة الفضاء باشكاله الفنية بعد أن جرد

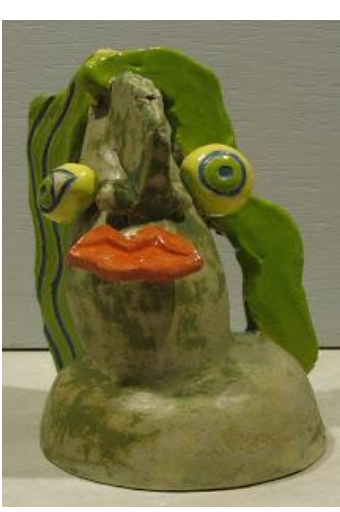
علاقاتها الحسية والموضوعية ليجعلها تحوم في فضاء غير محدد(5). ولم يبتعد الخزف عن طرئ طروحات

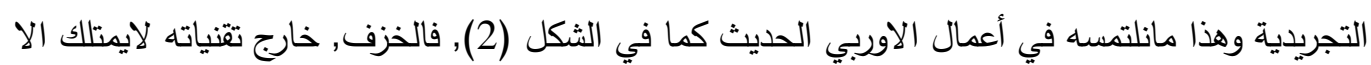

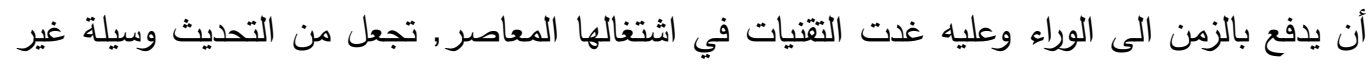

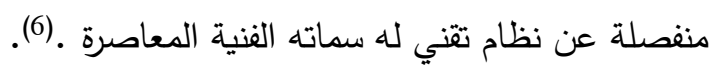
فالمنجز الخزفي ماهو إلا انفعالات وحالات تمارسها الوظيفة الطينية والفنية والنار والأكاسيد, المستقلة عن

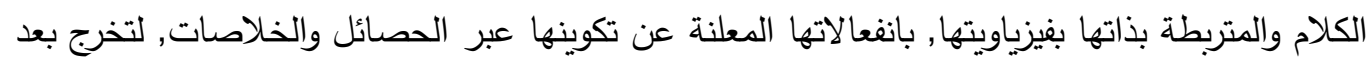

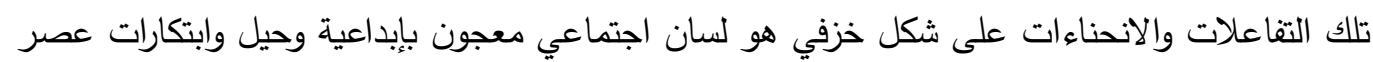
شكل (2) وخيرات متراكمة (7).

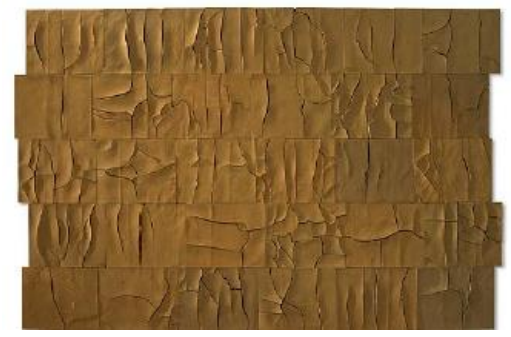

فالنظرة الفنية للخامة (الطين) هي وسيلة ذات قدرة تعبيرية غير محددة توظف في التعبير الجمالي فتلقائية المادة الخام جزء من قيمتها التعبيرية, فقد عمد بعض الخزافين الى في ترك لون الطينة دون أي اضافة بخشونتها وعتمتها وعدم انتظام التوزيع الحراري شكل (3).

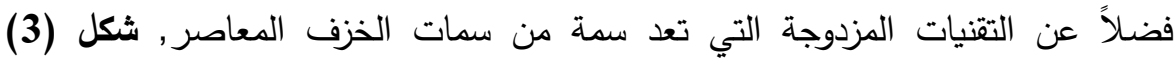

www.maqalaty.com, $1 / 4 / 2013$.

(1) (1) طارق, قصي: البنية الثكلية في الخزف:

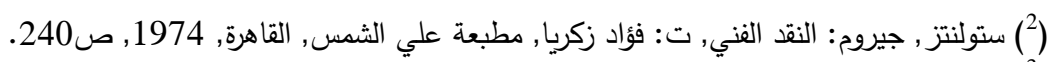

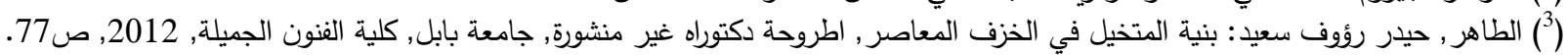

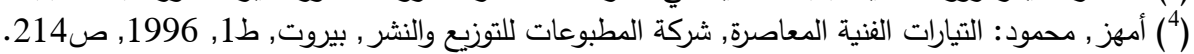

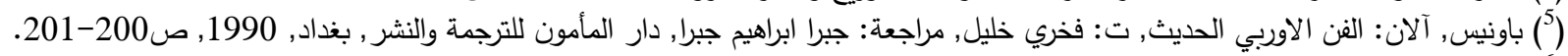

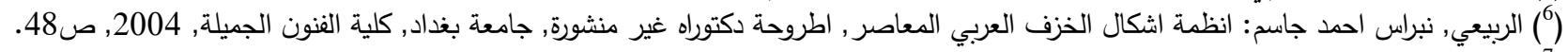

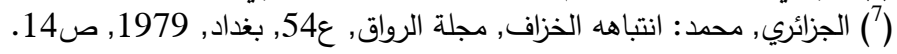




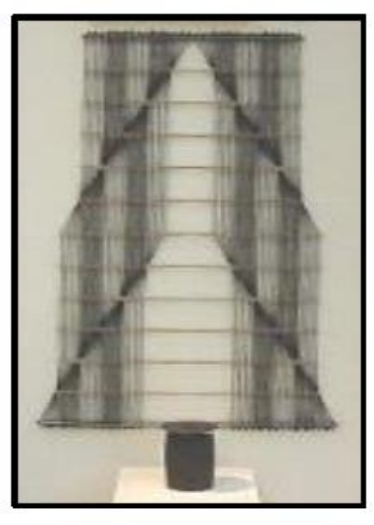

اذ فتح المجال امام هكذا أسلوب في التعبير البنائي التثكيلي, فقد استخدمت من مواد وتقنيات مختلفة يعتمد على المزاوجة بين الخصائص المرئية المثيرة والموحية أو المزاوجة بين أكثر من فن للتأثير المطلوب فئي

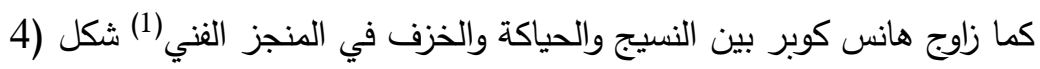

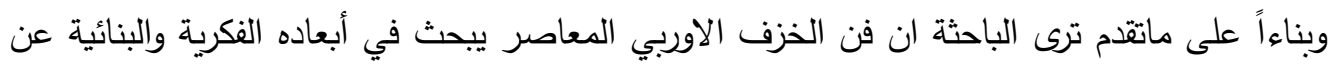

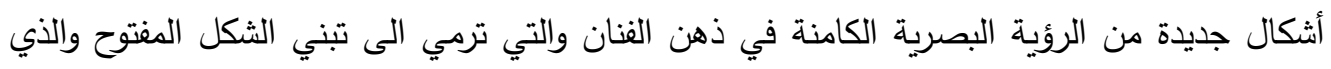

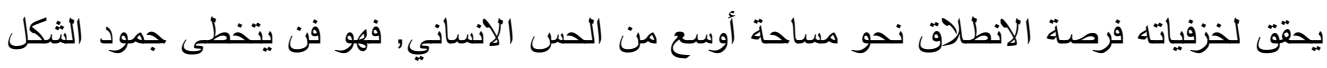

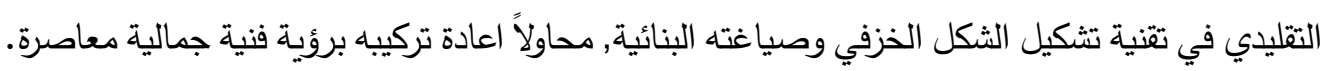

شكل (4) شعاصة

المبحث الثاني :الخزف الاوربي المعاصر سار الفن المعاصر بجدلية معينة فبدل مواضيعه وجدد لغته حسب الظروف المختلفة, مما أدى الى صعوبة تحديد ماهو الفن كنتاج

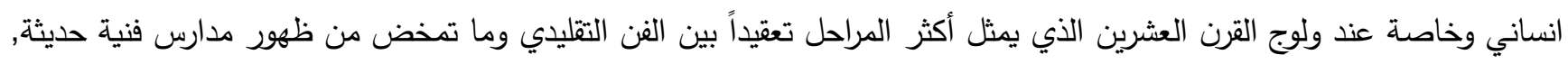
والتي اخذت كل منها أبعاد فكرية وبنائية مختلفة وجديدة, تعطي بدورها انطباعاً عن عالم الفن في القرن العشرين.

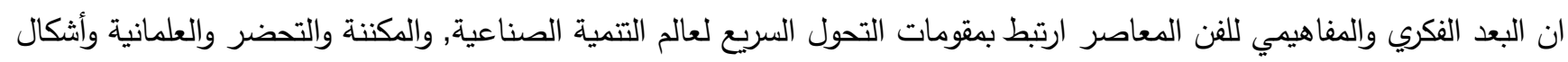

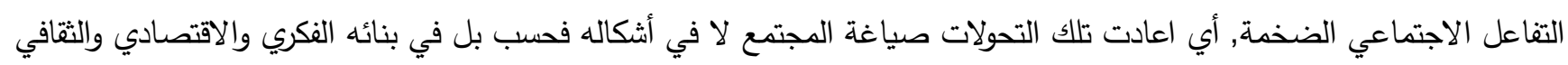

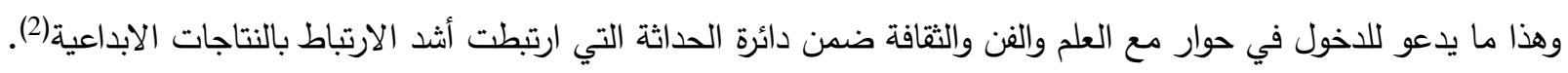
فعبر الفنان من خلال علاقته بمجتمعه عن تفاعلات فكرية ولدت سياقات حياتية مختلفة مما أضفت ملامح ثقافية لأفية لحضارة آنية, وهنا

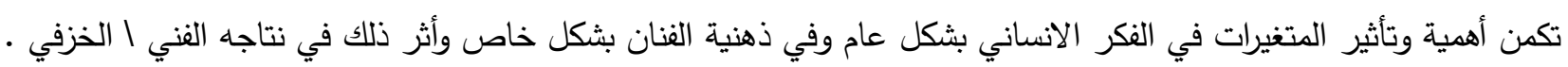

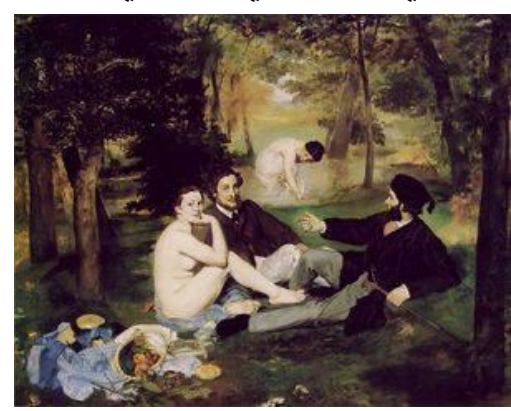

فأستلهم البعد الفكري للانطباعية عملية دخول الخطاب الواقعي في مجال المتع الحسية فئية وفئية

فيما يفضي عليه العناصر الفنية سموا جماليا وبذلك جاء الخطاب الواقعي تجسيدا لكل الافكار

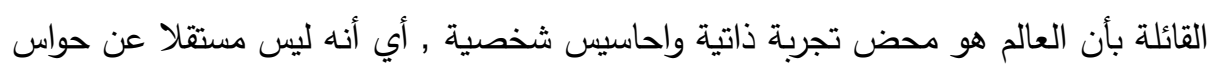

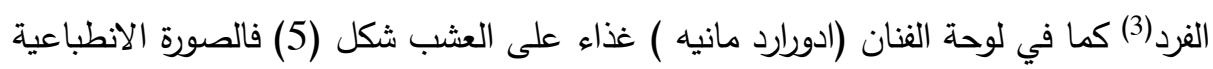

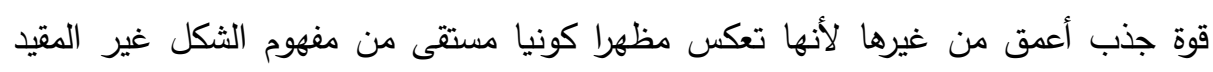
شكل (5) والمحدد والضوء النابض بالحرية.

وكان البعد الفكري للوحوشيون ورائده ماتيس معتمداً على اللون وجعل الفن متعة وراحة للانسان المتعب, شكل (6) وحقق بيكاسو فناً جديداً يسعى لكثف الواقع العميق بدل الواقع المرئي وحطم الثكل الظاهر نهائياً للوصول بأبعاده الفكرية الى فن فيه جانباً

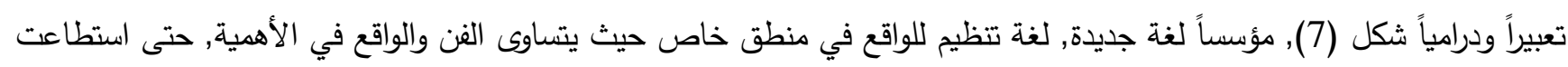
التكعيبية الى تقدم شكلاً جديداً من العلاقة بين الفن والواقع.

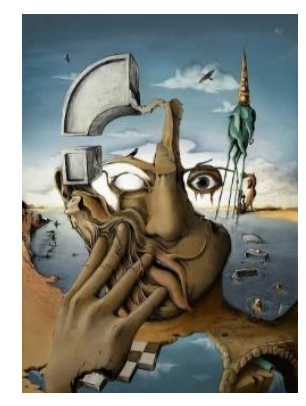

(7)

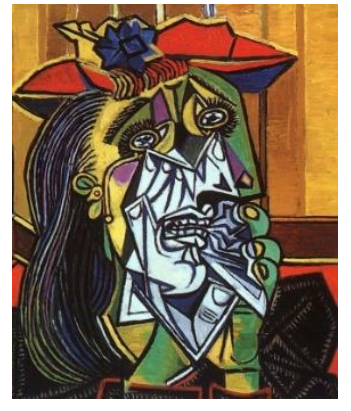

(6)

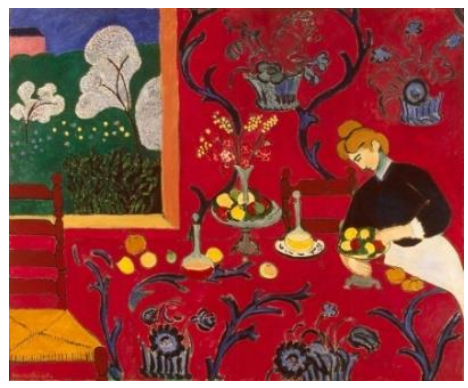

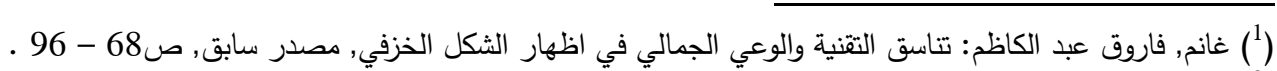

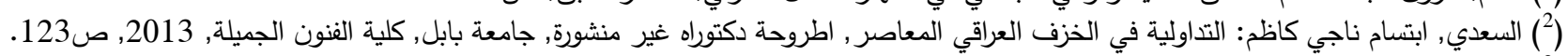

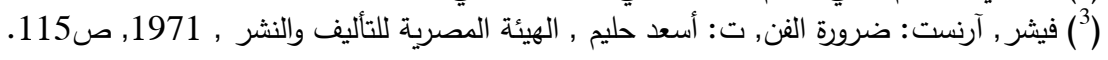


اما التجريد فيرفض أي صلة بين الفن والواقع, فالفنان أصبح يعبر عن مشاعره الذاتية وأفكاره بحرية مطلقة, ومثلتها حركة (الدادا) التي سعت الى الغاء الفن كله, من خلال انتاج فن يخالف كل القيم السائدة, ضمن حركة احتجاج على كل شيء, وأصبحت الاعمال الفنية

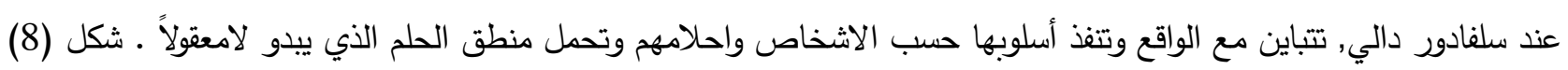
وعند البحث في الابعاد الفكرية والبنائية للفن عموماً والخزف خصوصاً, يقودنا بالضرورة الى البحث في الوعي والادرالك وماهو مؤسس نتاجاً للوعي والقصدية, ذلك ان الفن نظام فكري متحقق بآليات مادية تثكل بنية اظهاره والعلاقة بين الوسيط المادي والنتاج الظاهر هو انعكاس للصورة المتخيلة في ذهن الفنان واسقاطها بالمصصلة في نظام الفن الخزفي, لذلك يثكل كل من الجانب التبات التقني

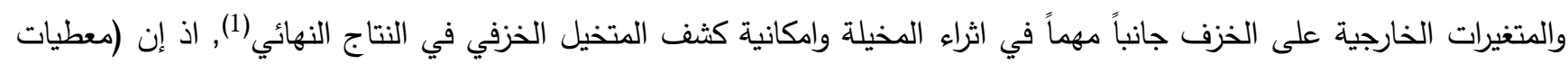

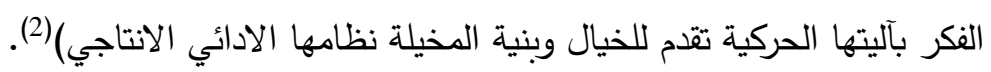
وعلى حد قول (هبرت ريد) يعمل الخزاف في فن احادي, إذ انه يصمم الفكرة ثم يعالج خامته ويحدد قوامها أو مرونتها مقدراً

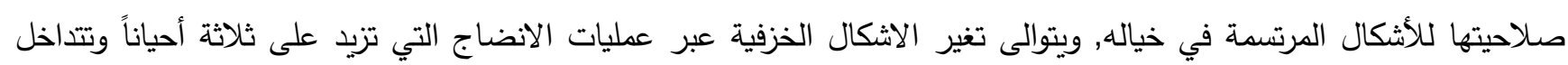

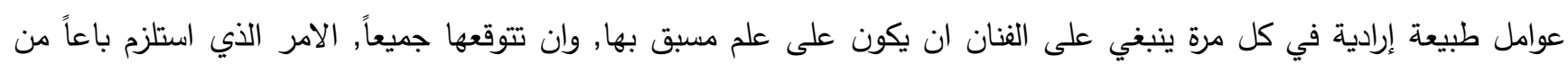
التجارب, لتصبح تلك العوامل في نطاق ارادته الحرة(3). فقد عالج الانسان شتى الافكار والموضوعات التي لاتتفصل عن قوة الوعي والادراك من خلال حركة الزمن وكذلك الوعي

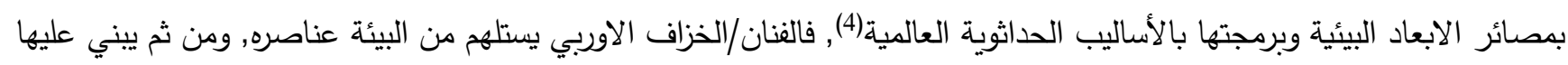
واقعاً مثالياً خيالياً من تصويره, فيزوغ الفكرة لديه تأتي عن طريق مؤثر خارجي يسرح فيه الفنان مسترجعاً الاشكال الكامنة في ذاكرته, ومن ثم يعمل على اضافة قيمة جديدة لها من ذاته(5). فالخزف الاوربي المعاصر يعمل ضمن سياق فكري, ذلك السياق الذي يضع الاعمال التقليدية على اساس رؤية فكرية وأسلوبية تكون عناصر ضاغطة ومحركة في اتجاهات فنية معاصرة لاتخرج من سياقها, لإرتباطها بقواعد ومفاهيم ورؤى معرفية تعمل في دائرة ذات فاعلية كبيرة نشأت على اساس تلك الأفكار . ان المنجز الخزفي الاوربي, داخل منظومة التعبير والاختلاف وبفعل تلك الآليات الدافعة للتحول نحو نظام اختلاف رؤيوي

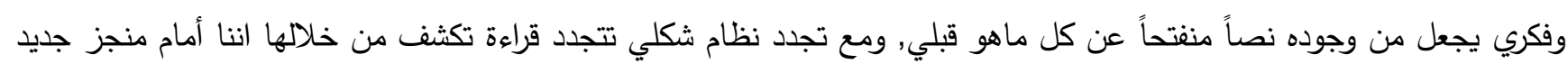
يختلف بكل معطياته الجمالية(6). وعلى الرغم من حداثة مفهوم التحول في التشكيل الخزفي الا ان توسع وانفتاح دلالاته على الاتجاهات

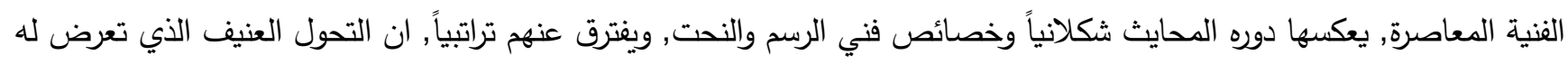

الخزف في دلالته المعرفية هو انتقاله من نمطية التقليد التداولي, نحو ابتداع سياقات أكثر حيوية ومفترقة عن علائقية سابقة (7).

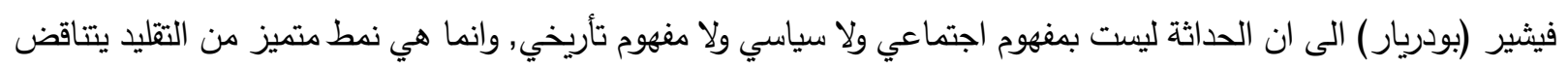
مع النمط السائد, يمتد في كل الميادين دولة وموسيقى وعادات وأفكار , تتحرك صيغها ومضامينها في الزمان ولان والمكان فأبعاده الفكرية لاترتسم من حالة الثبات والتأيقن في الماضي, انما هي تمثل سلسلة من التحولات في المجتمع المعاصر قائمة على أساس التمدن والتصنيع والتطور التكنولوجي (8). أي أخذت بما هو جديد ومغاير للقديم, لأن الجديد لايمكن أن يكون ثابتاً, فالحداثة تهتم بالتجدد الدائم, باحثة في أبعادها الفكرية

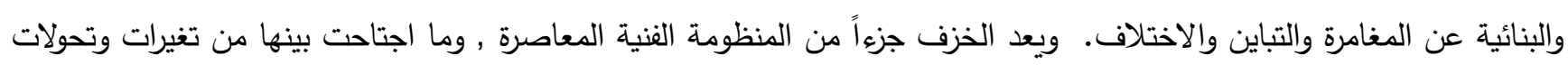

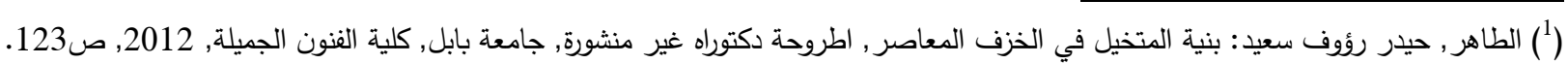

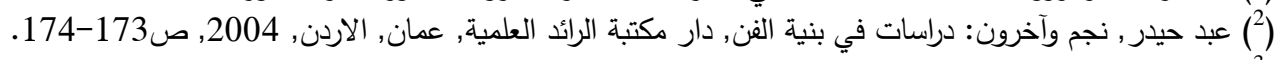

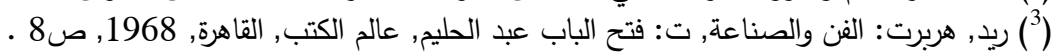

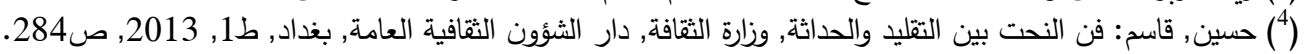

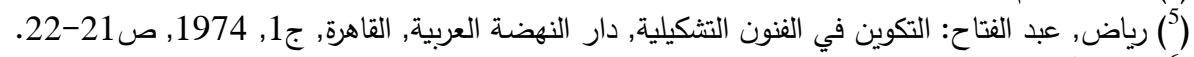

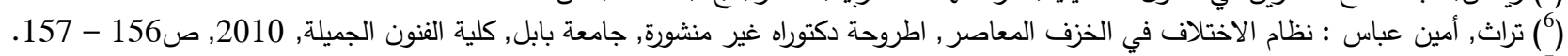

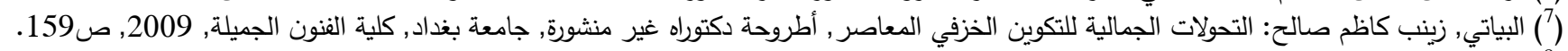

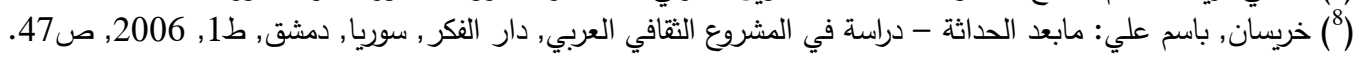


على المستوى الفكري والتقني, فأنطوت بنية المنجز الخزفي على قدر عال من الحرية في صياغة تمظهراته, اذ أعطت الصبغة اللونية الكيميائية بعداً جمالياً آخر للبعد الذي يتصف به شكله, ليرتبط باللحظة المتغايرة في محاولة الامساك بهاب(1). ان ماقدمته الطروحات الفنية المعاصرة من أنظمة فكرية ساهمت في تنوع الاشكال الخزفية مما أظهر لنا لئها اضافات شكلية لاتدخل في جوهرية الاداء الوظيفي, فظهرت خزفيات تمثل سمة الفن الخالص وهذا مايؤكد قول كانت (ان الحكم الجمالي ليس ذا نفع عملي أن هدف الفن لايرمي الا الى الامتناع الجمالي الخالص), الجميل لذات الجمال, فأضفى ثراءاً دلالياً على الانظمة الفكرية للثكل الخزفي (2). فالثكل الخزفي المعاصر بدأ يبحث في تغيير نظام الثكل التقليدي في ذهنية المتلقي, خارجاً من اطاره الضيق الى التعددية والتتوع في أبعاده الفكرية والبنائية , مما غير صورة المنجز الخزفي التقليدي لاستشارة ذاتية المتلقي وذهنيته.

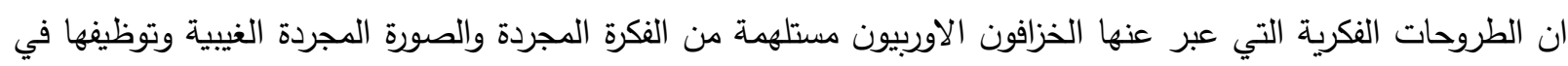
بنية العمل الخزفي, فنجد الخزاف يضيف اقتراحات شكلية, سوغت انتزاعه لها كحصيلة مشروطة بتصورات خاصة ومرجعيات ذاتية

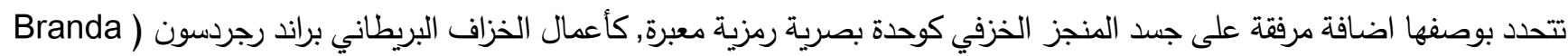
(Richardson علاقات بنائية جديدة تمتاز بالتجديد الهندسي, وتحرر الذات المتخيلة من سلطة الموضوعية شكل (9), وأسقط الخزاف الايطالي ستيفانو ديلا (Stefano Della) معطى الطبيعة الجمالي واستبدله بمعطى جمالي آخر هو بقايا السجائر وخالقاً بهذا المنجز الجمالي بيئة مضادة, فالجمال يمكن العثور عليه في مكان آخر غير موجودات الطبيعة, متخطياً اليات فن الخزف وانسحابه الى اليات تتفيذ جديدة على مستوى الثكل والتقنية شكل (10) وعمد الخزاف البريطاني (اليسون بريتون) (Alison Britton) الى تفكيك منجزه الخزفي وتحليله ومن ثم اعادة تركيبه هندسياً حيث تتداخل فيه السطوح الجانبية والامامية المرسومة والمجسمة في ذات الوقت, ليحقق متعه ورؤية جمالية وفكرية جديدة, مبتعداً عن الالتزام الكامل بالقواعد الكلاسيكية المتعارف عليها في تصوير الواقع شكل (11) فئليس هناك التزام في الفن لأن الفن دائماً حر ...وفي الفن الحقيقي لاتسبق النظرية الممارسة ولكنها تتبعها)(3).

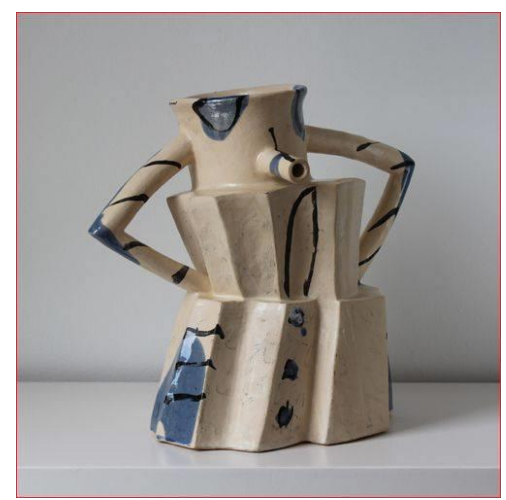

شكل (11)

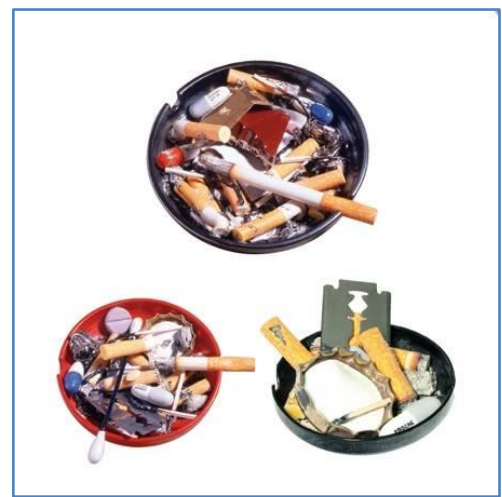

شكل (10)

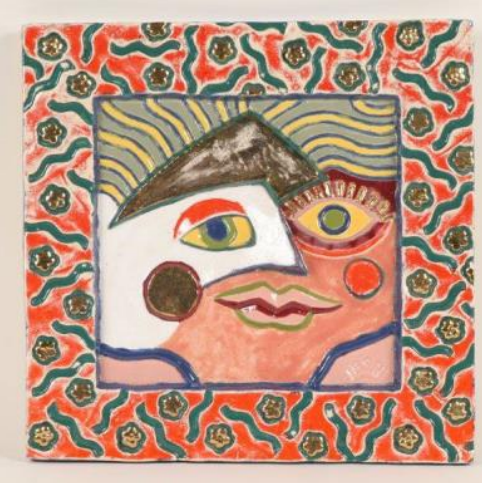

شكل (9)

لتتشكل بذلك هوية الأشكال الخزفية على أسس منطقية رياضية, فالخط واللون والكتلة أفصحوا عن جوهر الفن وهذا مانراه

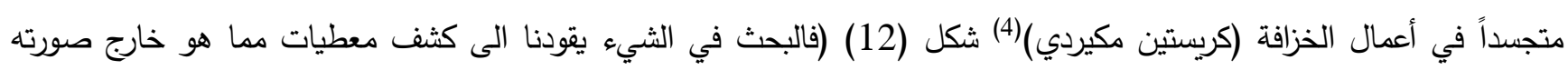
المظهرية, ان للشيء معنى أكثر من مظهره المرئي اذا ماركب بما يجاوره(5). وهذا مانجده في أعمال الخزاف البريطاني جون مدلميس

(13) شكلى (Jon Middlemiss)

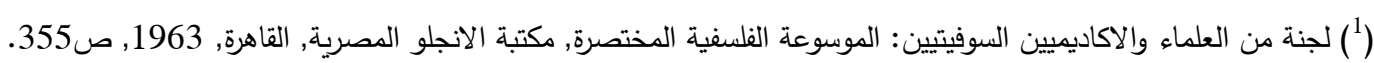

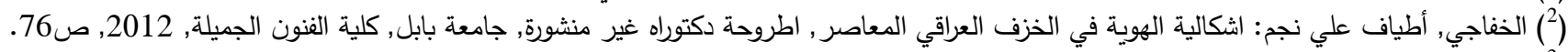

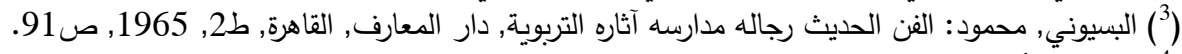

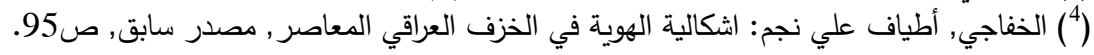
(5) Groh mamn, Will:klee, New York: harryn, abrams. Int. P.84. 

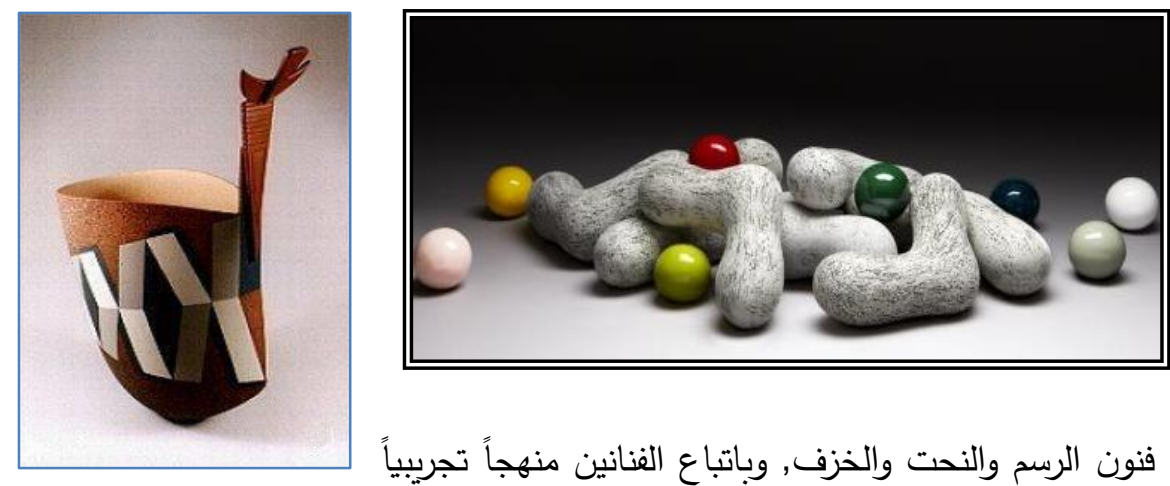

شكل (12) شكل (13) (12)

وابتعد الخزاف الاماني هانز

كوبر (Hans Coper) في عمله الخزفي

عن المقاييس أو الانساق الثكلية المتداولة

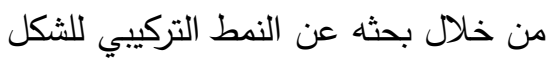
الواحد. شكل(14), فكان للتحولات المعرفية

والتطور العلمي والفلسفات الجديدة أثرها في فنون الرسم والنحت والخزف, وباتباع الفنانين منهجاً تجريبياً جديداً, فأصبح الفن الذي كان في السابق يحاكي الطبيعة ويصور العالم كي ينقل الينا نموذجاً عنه مثالياً وبات الان يتعامل مع الفكرة والثعور أو الحس أو مايسيه (فاسيلي كاندنسكي) الضرورة الداخلية في محاولة لجعل اللامرئي مرئياً بحسب تعبير بولي كلي ( Paul شكل (14)

${ }^{(1)}($ Klee

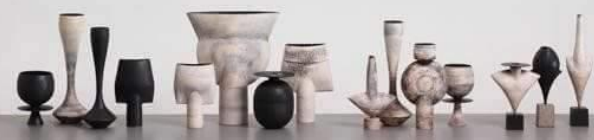
ولم يكن الخطاب الخزفي بمعزل عن هذه الافكار فقد أكد الخزاف السويدي جرس فيسيني (Chris Vicini) على الفوضى والعبث, مانحاً خطابه الفني/الخزفي توصيفات متخيله تتصف بالغرابة وتتضوي وفق خطاب تثكيلي اعتمد في طروحاته

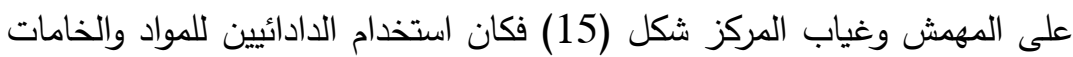

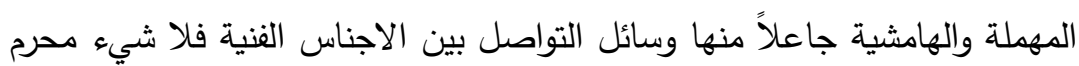
بل يمكن استخدام كل شيء بوصفه خطاباً لتعبر عن احساس وفكرة عابرة(2), فهم مستعدون لاستخدام أي وسيلة ضمن الخيال كما في

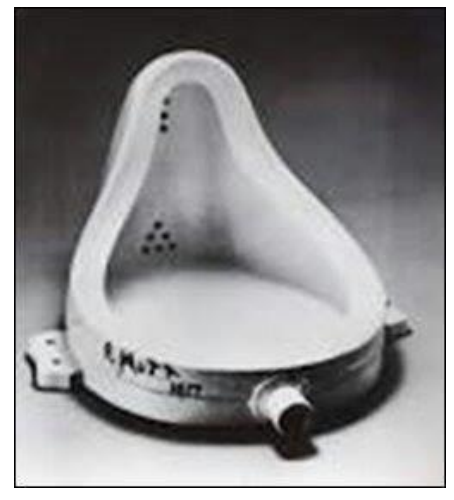

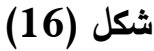

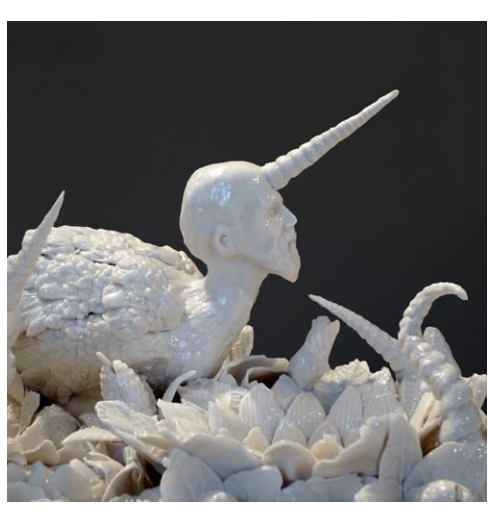

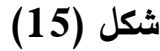

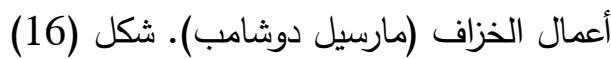

ان أوربا كانت منطلق الانقلابات في الرؤية والاسلوب والتي حقتت قيمة الانزياحات الثكلية التي أسست تلك التشكيلات وتركيباتها, وان الانتقال الثقافي والحضاري بين الثعوب واختلاف البيئة المكانية والزمانية واختلاف الرؤية والابعاد أسس أشكالاً أخرى وتتنيات متنوعة من الخزف(3).

ومما تقدم ترى الباحثة ان الفن المعاصر قد ساهم في اخراج المنجز الخزفي من اطاره الضيق الى التعددية والتتوع في الدلالة والتقنية,

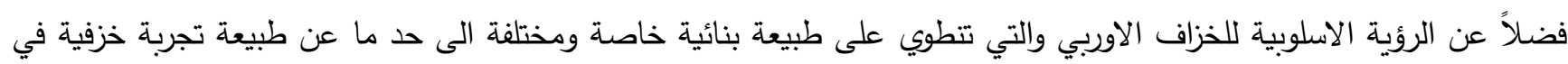
بلدان أخرى.

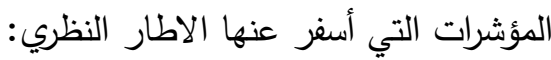
1. مقت البعد الفكري المعاصر فكرة الانسجام والتداخل مابين المعطيات الفنية والجمالية والفلسفية على حد سواء .

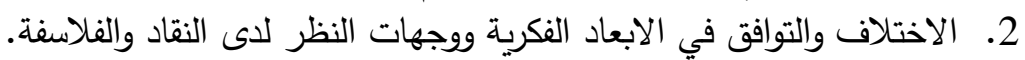

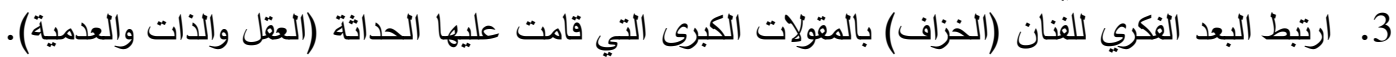
4. حول الفنان (الخزاف) بأبعاده الفكرية والبنائية منجزه الخزفي الى فضاء الفئ تخيلي واسع بامتصاص مشاعره التي دفعت بفن الخزف ولات

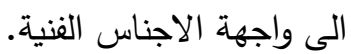

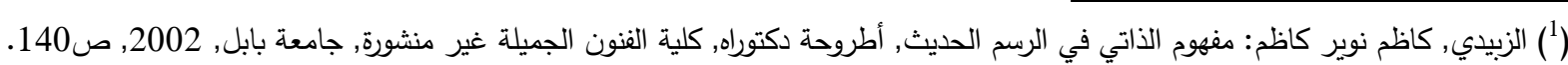

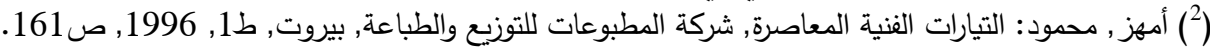

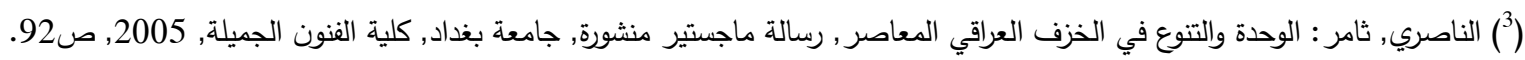


5. تداخل الاجناس مع بعضها سيعمل على تأسيس التعددية والتتوع في بنائي فكري جديد قائم على أساس التعددية والتتوع في

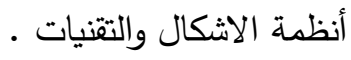

6. ميل الفن بالأبعاد الفكرية والبنائية الى الخيالي أو الافتراضي كجزء من خصوصيته ووظيفته كما في الفن التكعيبي. 7. يمثل البعد الفكري والبنائي للمنجز الخزفي انفعالات وحالات يمارسها الخزاف باستخدام خامته (الطين والنار والاكاسيد). 8. يبحث فن الخزف الاوربي المعاصر بأبعاده الفكرية والبنائية عن أشكال جديدة من الرؤية البصرية والتي ترمي الى تبني الثكل المفتوح, لتخطي جمود الثكل التقليدي في تقنية تثكيل الثكل الخزفي وصياغته البنائية. 9. تعد البنية الثكلية من أهم البناءات المكونة للمنجز الخزفي, الذي يمكن عده المترجم الأساس لأفكار الفنان وذاته. 10. عمد الخزاف الاوربي الى تفكيك الثكل واعادة تركيبه هندسياً ليحقق رؤية جمالية جديدة. 11. انطوت بنية المنجز الخزفي بأبعاده الفكرية والبنائية على قدر عالٍ من الحرية في صياغة التيه تمظهراته فكان للصيغة اللونية بعداً

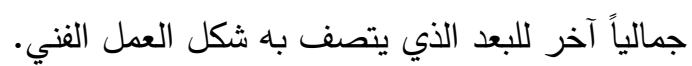
ان الابعاد الفكرية للحداثة حسب (بودريار) لاترتسم في حالة الثبات والتأيقن في الماضِ, انما تمثل سلسلة من التحولات في .12 المجتمع المعاصر قائمة على أساس التمدن والتصنيع والتطور التكنولوجي. 13. حاول الفنان (الخزاف) الاوربي المعاصر ابراز التصميم البنائي واعتماده عناصر الثكل وفق وفيع مفاهيم شمولية كونية كالاتزان والتجانس والتتاغم والايقاع. 14. يتميز البعد الفكري للحداثة بالنفور والانزياح من كل مماهاة وتتميط, فهو ثورة مستمرة وتجاوز مستمر وتجديد من أجل التجديد.

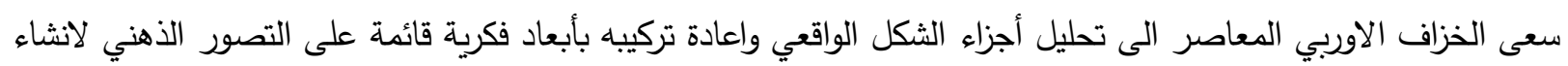

علاقات بنائية تمتاز بالتجريد الهندسي وتحرير الذات المتخيلة من سلطة الموضوعية. 16. اعتمدت بعض الأعمال الخزفية في أبعادها الفكرية والبنائية على الفوضى والعبث, مانحة خطابها الفني (الخزفي) توصيفات

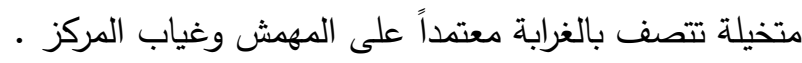
الدراسات السابقة ومناقتشها :

بعد الجهد الذي بذلته الباحثة بالاطلاع والبحث في مجموعة الرسائل والاطاريح والبحوث المنشورة وغير المنشورة , والتصفح في شبكة الانترنت , لم تجد الباحثة دراسة سابقة تقترب من البحث الحالي في حدود مشكلته وهدفه ونتائجه . الفصل الثالث إجراءات البحث

اولاً: مجتمع البحث: يمثل مجتمع البحث مجموعة من الاعمال الفنية (الخزفيه) للخزافين الأوربين المعاصرين وعلى وفق الفترة المحددة من (1990-2000) والبالغ (35) خمسة وثلاثون عملاً خزفياً. والذي تيسر للباحثه الاطلاع عليها من الكتب الاجنبية والمجلات فضلاً عن شبكه الانترنت لاغراض البحث الحالي. ثانياً: عينة البحث: قامت الباحثة باختيار عينة البحث بصورة قصدية والبالغ عددها (5) خمسة أعمال خزفية وفقاً للمبررات الاتية:1- استبعاد الاعمال الخزفية التي تكررت في مواضيعها الفكريه والبنائية. 2- وجود التتوع التقني والفني والتباين في الافكار والاساليب الفنية.

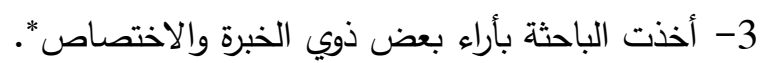

ثالثاً: هدف البحث: من اجل تحقيق هدف البحث والتعرف على الابعاد الفكرية والبنائية للخزف الاوربي المعاصر , اعتمدت الباحثه بأه المؤشرات التي أسفر عنها الأطار النظري بوصفها أداة البحث أستندت عليها الباحثه في الية التحليل.

2 * أ. أ. د عبد الحميد فاضل / نحت / كلية الفنون الجميلة / جامعه بابل.

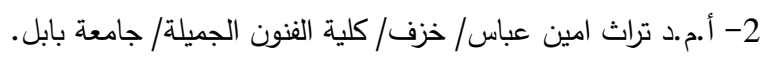
3- أ.م.د سامر أحمد الكرادي/ خزف كرئ كلية الفنون الجميلة/ جامعة بابل. 
رابعاً: منهج البحث: اعتمدت الباحثة المنهج الوصفي - طريقه التحليل منهجاً لدراسة الابعاد الفكريه والبنائيه للخزف الاوربي

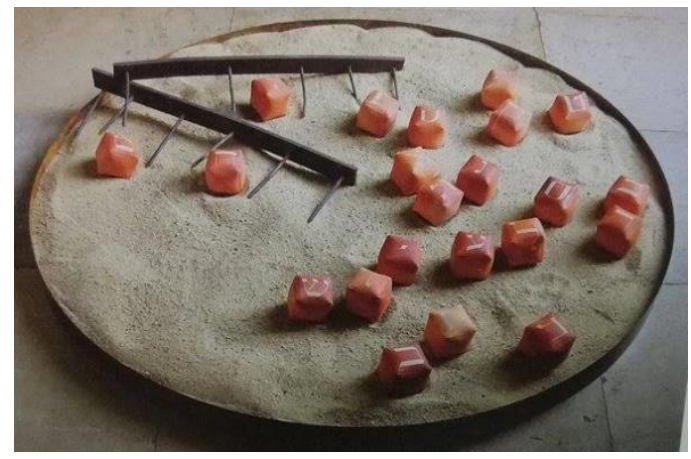

- (المعاصر

(1) (نموذج

Gabriele Putz اسم الفنان: جبرائيل باتس

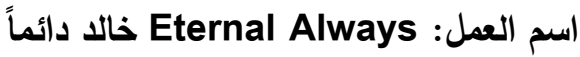
قياسات العمل: 100CM 1992 : سنة الانجاز بلد الانجاز : المانيا يمثل هذا النموذج منجزاً خزفياً مؤلفاً من تجميع عدة اشكال هندسية في بنية واحدة, يتكون من صحن دائري الثكل من الحديد ممتلئ بالرمل, مع وجود مجموعة من المكعبات الخزفية ذات لون واحد البرتقالي بتدرج يشبه الى حد كبير مفاتيح الكيبور , رسم عليها بعض الرموز والحروف, وعلى حافه الصحن عودان من الخشب ثبت على العود الاول خمسة مسامير حديدية وعلى العود الاخر ستة مسامير حديدية اخرى. لم يعبر المنجز الفني للخزاف (Gabriele Putz) عن فكرة او مفهوم معين بحد ذاته, بل ارتبط منجزه الخزفي بأبعادة الفكرية

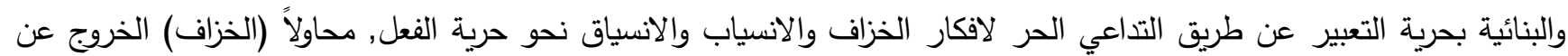
النمط التقليدي في البعد الفكري والبنائي للمنجزه الخزفي الى اللامألوفية واللامتوقع. فكثف البعد البنائي عن اسقاطات اللاوعي لاى الخزاف والتي يبدو فيها الثكل متخذاً صيغة بنائية تصادفية جمالية فضلاً عن العفوية والارتجال الذي قاد نحو تثتيت المنظومة البصرية والغاء المركز الثابت, عبر عدمية التنظيم (ما دعا اليه نيتشه) الثكلي

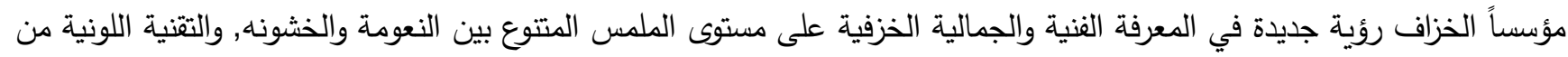
خلال استخدامه الوان الاكريلك (البرتقالي) بعد فخرها بدرجه حرارة 1060c في الفرن الكهبائي, محققاً من خلال تقنيته الخزفيه دهشة رؤيوية للمتلقي نتيجة الاتجاه المستمر نحو اللامألوفية واللامظهرية. فقد اظهر المنجز الخزفي للخزاف (Gabriele Putz) ابعاداً بنائية هندسية تمثلت في (الصحن الدائري, المكعبات, الاعواد).

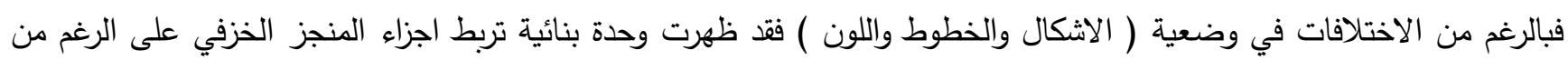

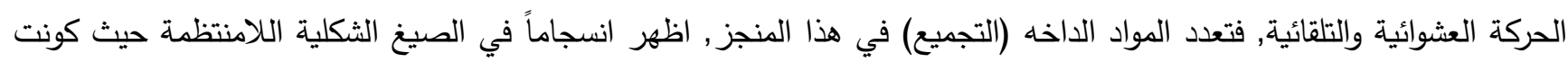
علاقه تتابعية في استخراج انماط شكلية متوالده عن بعضها البعض في ذاتية فات السياق البنائي وهذا من شأنه ان يعزز الوحدة البنائية في

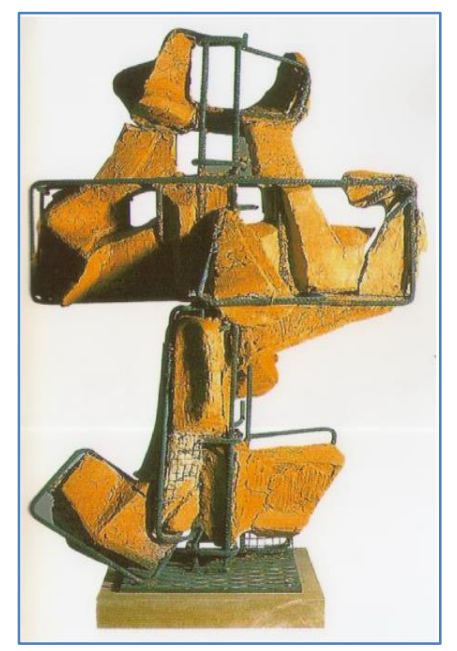
المنجز الخزفي بشكله العام. وهكذا فقد عمد الخزاف على اخراج منجزه الخزفي بابعادة الفكريه والبنائية بثكل جديد من

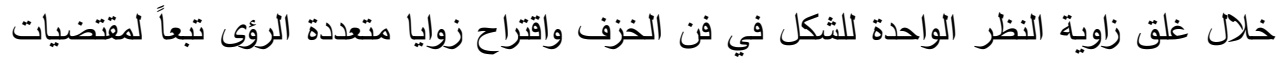
التعبير التي تحدث في الابعاد الفكرية والبنائية للفن المعاصر .

(2) (نموذج

اسم الفنان: اندريـه كاريوسو Andrea Caruso اسم العمل: تكوينات مجردة قياسات العمل: 183 CM

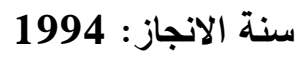
بلا الانجاز : ايطاليا ان النظام الذي خضعت له بنائية المنجز الخزفي هنا, قد أتخذ طابعاً تجريدياً, رُكب على هيكل من الحديد ذا لون واحد (البنّي). يمتلك المنجز الفني للخزاف (Andrea caruso) في ابعادة الفكرية والبنائية قوة اقناع تلقائية وديناميكية تدل على مهارة متنامية 
ومخيلة منفتحة لهذ الخزاف, فالثكل الخارجي للمنجز الخزفي يعطي ايحاءاً معمارياً هندسياً 0مربعات, مستطيلات, مثلث) غير منتظمة يعززه اللون البني, متجاوزاً الخزاف أُطر الثكل المألوف, حتى بدت بنية المنجز الخزفي تتلائم مع كسر نمطية الصورة التقليدية للبناء

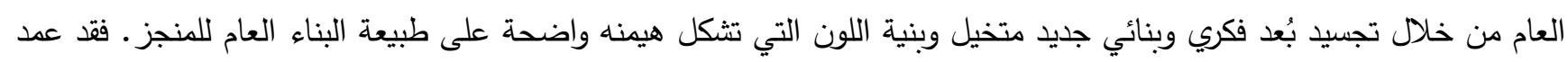

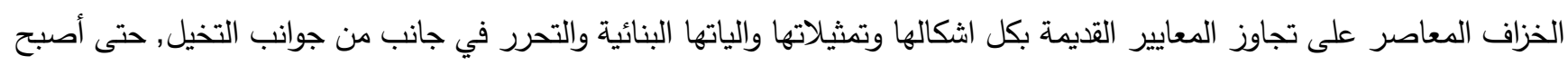

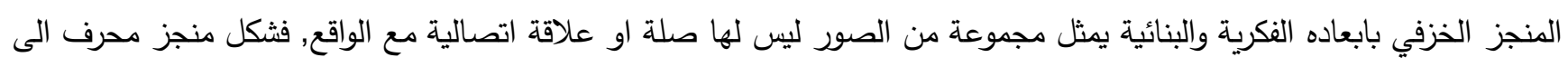

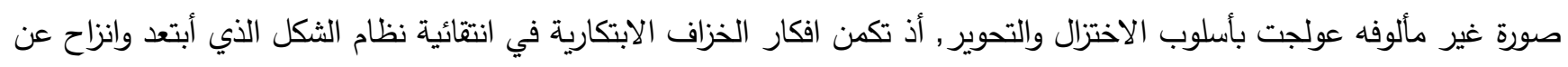
المحاكاة.

أذ ينتمي المنجز الخزفي في نظامه كثكل تجريدي لمنحى تكعيبي حيث المفارقة القصدية للواقع والانفصال عنه بل هو نوع من التمرد في اسلوب الطرح كما هو واقعي (مشخص) فأن ما يطرحه البعد الفكري والبنائي للمنجز الخزفي ذي الطابع التكعيبي هنا, واقعاً افتراضياً وليس واقعاً مرئياً, فالمتخيل الخزفي للخزاف (Andrea CARUSO) اراد من انجازه ان يدرك ذهنياً دون أي معونه

فالعناصر الفنيه هنا نجدها قد تحررت من القيود التشخيصية وشرعت تستقي حياه خالصة بها من خلال تفعيل دورها الايجابي في تمثلات الثكل التجريدي الهندسي (حققت فرضها البنائي في الثكل التجريدي الخالص), اما عنصر اللون (البني) الخشنة اتى استكمالاً ايضاً لهذه الرؤيه الجمالية التجريدية.

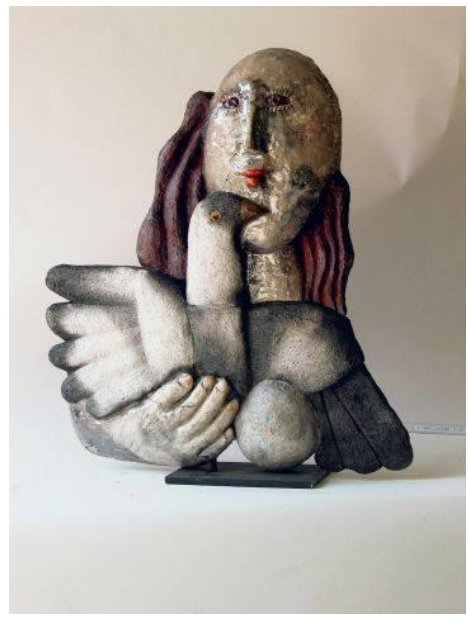
وهكذا ينهض المنجز الخزفي التجريدي في هذا النموذج بابعاده الفكريه والبنائيه على اسلوب لهونه

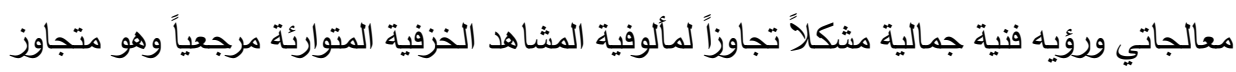

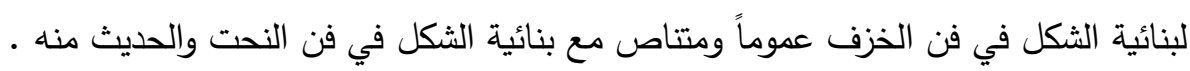

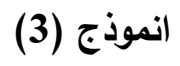

Roger capron اسم الفنان: روجر كابرون

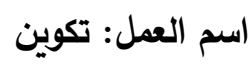

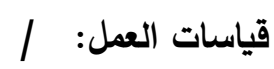

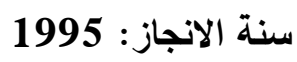

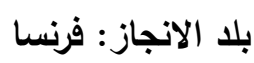
عند مشاهدة التكوين الظاهري لهذا المنجز الخزفي, نجده يمثل تكونين الاول بشرى والثاني حيواني, الاول يمثل رأس فتاة ذات

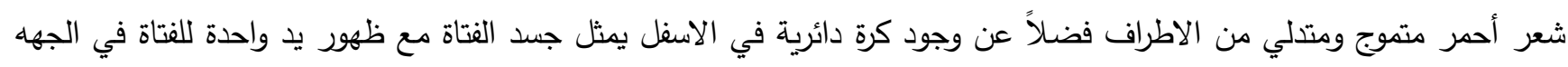

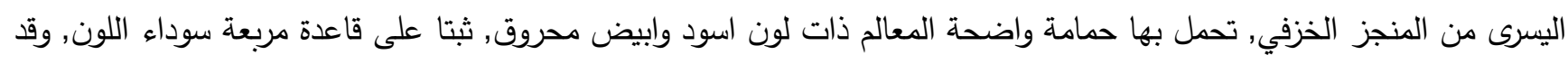
تم تتفيذ المنجز الخزفي بتقنية الراكو (Raku). فالمنجز الفني بأبعاده الفكرية والبنائيه للخزاف (capron) قد أعطى اهميه خاصة للحمامة (بحجمها الكبير ) من خلال حمل الفتاة لها, فثمة علاقة تربط الفتاة بالحمامة, علاقه لها دلالاتها الانسانية العميقة فالمرأة (الفتاة) تحمل طاقة عاطفية الفاهية وجمالية ونفسية

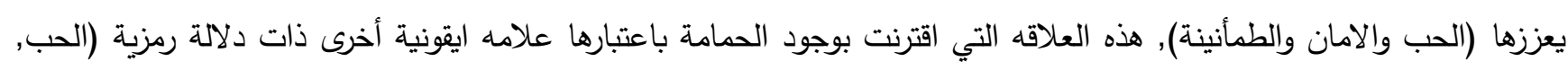
الحرية, السلام).

وهنا نجد ان البناء الثكلي للموضوع قد اقترب من مضمون الفكرة, بحيث يكون الثكل دلالة موضوعية لفكرة النجز الخزفي,

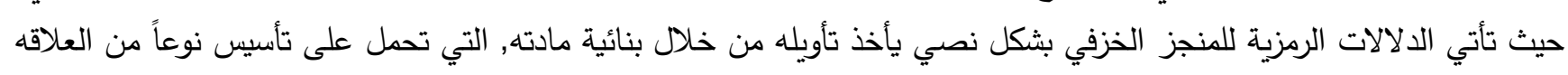

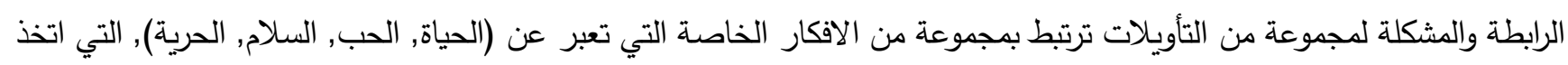

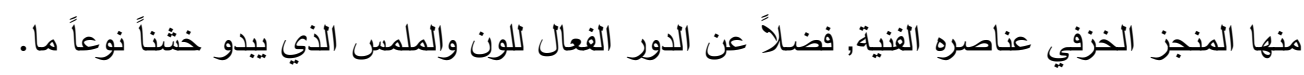


فالخزاف (Capron) نفد منجزه الخزفي بأستخدام اليد وبطريقة الاشرطة ومن ثم حرقها في درجات الحرارة العالية ( stone

were اذ تم الاختزال عن طريق حرق الكحول داخل الفرن لاحداث تزجيج الراكو (Raku). في هذا المنجز الخزفي ثمة استلاب مفاهيمي اكده (Capron). ضمن خاصية الارتكان لبواعث الدالالة المعرفية للتكوين العام

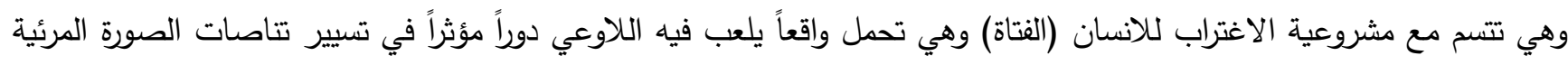
الى معطى جديد.

فاللاوعي في هذا المنجز الخزفي يتجلى في استخداماته للاشكال الواعية (الواقعية) بالطريقة التي تكتسب تساميها وانفتاحها على اللاوعي من خلال عنصر الخيال الذي يحول الاشكال (الفتاة والحمامة) من حقيقتها المكانية الوظيفية الى حقيقة جمالية مطلقة,

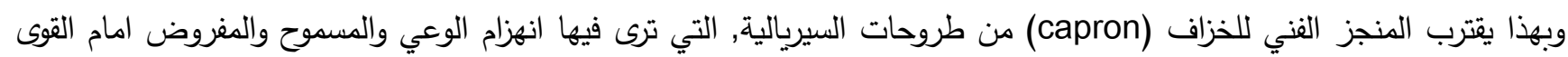
الاخلية المتحررة في نفس كل انسان. وبناءاً على ما تقدم نجد ان الخزاف (capron) ومن خلال منجزه الخزفي قد رجح لفكرة المتخيلة اللاواعية عل الفكرة العقلية الواعية, فعلى الرغم من استعارة الخزاف لاشكال واقعية (حسية) الا انه نجح في اكسابها قدرة الانزياح والتغريب النسبي والتعبير المرمز لاحداث الدهشة والمفاجأة دون الوقوف على حيثيات العالم الحسي او قوى العقل وتمثلاته.

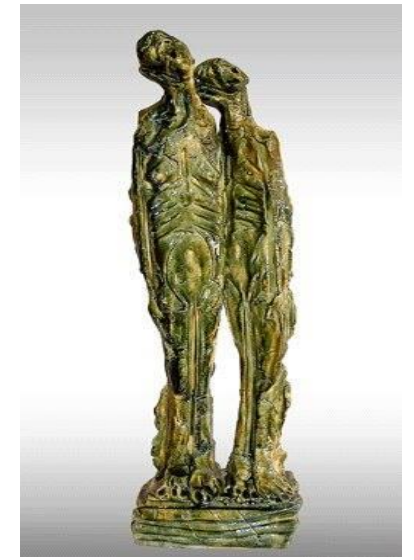

(4) (4) (4)

lan Gregory اسم الفنان: ايان جركوري اسم العمل: تكوين القياسات العمل: 64CM سنة الانجاز : 1998 بلد الانجاز : بربطانيا

يمثل المنجز الخزفي تكوينين ذو بنية واقعية تعبيرية, يمثلان شخصين بحجمين مختلفين بوضعيه الوقوف على قاعدة مربعة

الثكل, غلب عليهما اللون (الاخضر المائل الى الصفار) الذي احتل النص بكامله وقد نفذ المنجز الخزفي بتقنية الراكو (Raku) . يقوم المنجز الفني للخزاف (lan Gregory) بأبعاده الفكرية والبنائية على ثنائية إنسانية عرفها الوجود عبر دلالات كل منهما البايولوجية والسيكولوجية , فقد جسد الخزاف منجزه الفني من خلال جعل الكتلة التي تمثل الرجل اكبر حجماً من الكتلة التي تمثل المرأة,

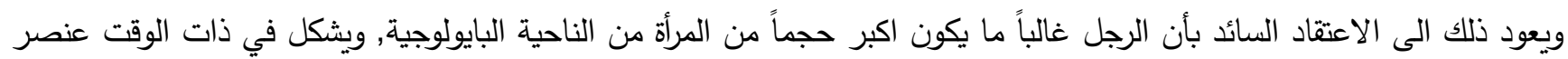
السيادة والقوة لهذه العلاقه الثنائية, أذ تبدو الكتلتان ذات جماليه مختزلة يعززه اللون الاخضر المائل الى الصفار مع الملمس المتعرج نوعاً ما, ويصل حجم الكتلة المتمثلة بالرجل والمرأة في المنجز بعموديته بُعداً فكرياً له دلالاته الواسعة (متعدد القراءات) (يادعا اليه لئه

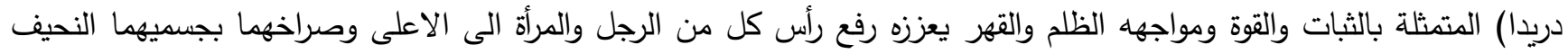

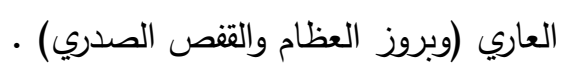

فالانسان هو المحور الذي يدور عليه المنجز الخزفي بأبعادة الفكرية والبنائية, اذ يحاول الخزاف أن يقترب من الواقع بتععيل ما هو متخيل في نظام من الاشكال التشخيصية (الرجل والمرأة). يؤكدها غياب ملامح الوجه واليدين والرجلين, فقد تم تثكيل المنجز الخزفي بطريقة البناء في جو حرق اختزالي لتحقيق التطابق والتماثل بين الكتلتين (الرجل والمرأة) الى حد ما. حيث ان اتجاه البعد الفكري المتخيل كفعل ابداعي في هذا المنجز الخزفي يؤشر لظهور نمط جديد من البناءات النحتية الخزفية

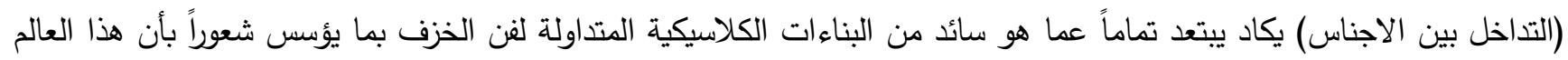
هو الذي يضمن للفنان / الخزاف حرية الاداء التعبيري وعلى حد قول هربرات ريد (ان التعبيرية هي تلك النموذج من الفن التي تُجاهد لتجسيد, ليس الوقائع, ولكن لتجسيد المشاعر الذاتية للفنان, انها حسب تحديد الكلمة فردانية, وهي على الاطلاق ظاهرة عصرية مميزه 


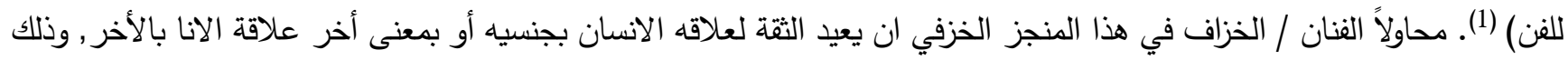
من خلال تلك التعبيرية العالية التي يبثها هذا المنجز الفني / الخزفي في التصاق التكوينين البشريين احدهما بالاخر .

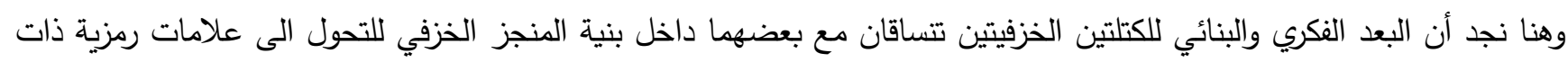

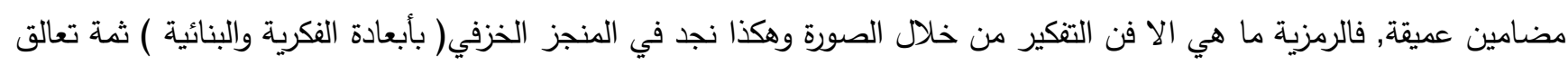
بين الكتلتين فالكتله بمفردها لا يمكن قراءتها داخل المنجز الخزفي لعدم وضوح معناهاً, فلابد من قراءتها مرتبطه مجتمعه معاً.

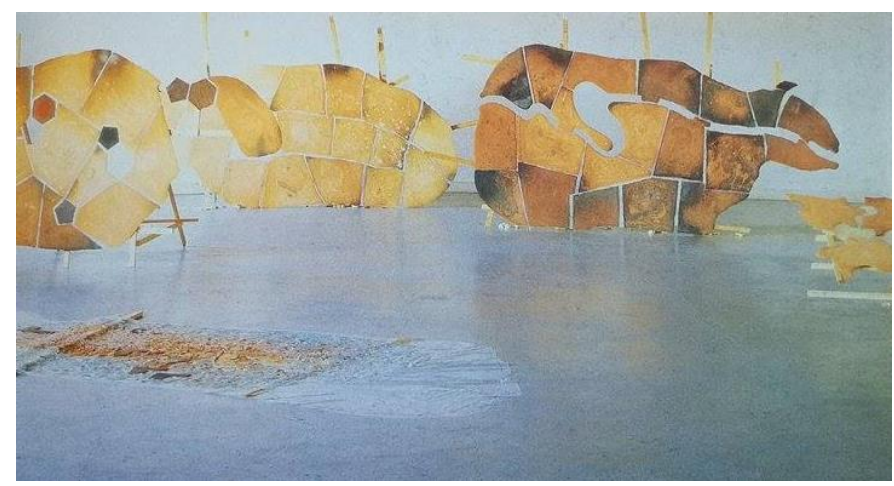

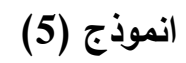

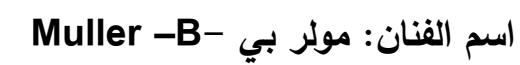

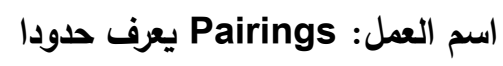
قياسات العمل: (320×200×1CM). سنه الانجاز : 2000 بلد الانجاز : سويسرا.

يمثل المنجز الفني تكويناً خزفياً, أتخذ شكلاً حيوانياً (بقرات) مجرداً, مفرغ من الداخل اشبه ما يكون بعمل فني بارز او لوحة

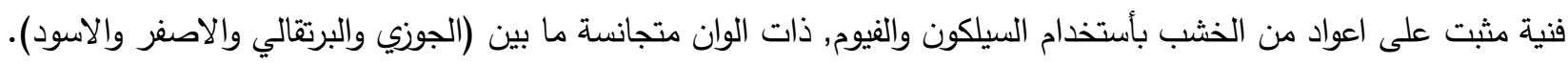
ابتعد الخزاف في ابعاده الفكرية والبنائية في هذا المنجز الخزفي عن السياقات المألوفة في الخزف التقليدي ليس فقط من من ناحية التشكيل, وانما من ناحية الفكرة, اذ أنه يبحث عن مضمون مضمر في المنجز الخزفي تاركاً التأثير للتشكيل لخلق جانباً ابداعياً جمالياً

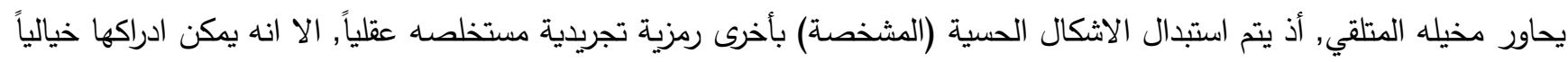

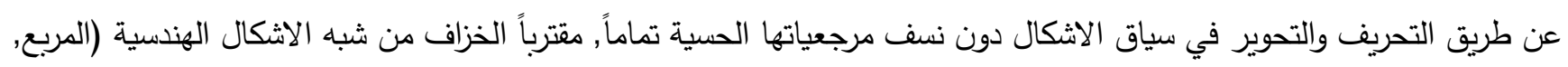
المعين) التجريدية مع بيان اختزاليه التثكيل والتكوين.

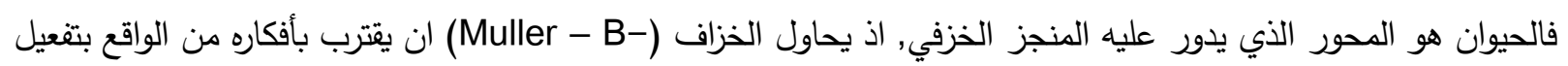

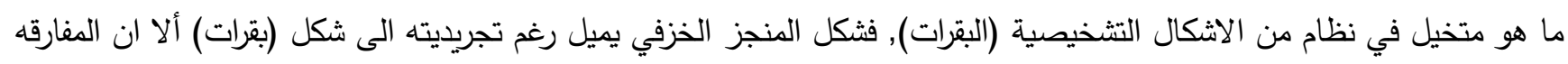

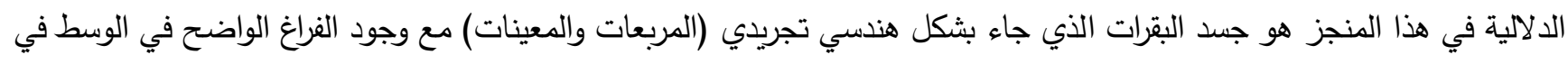
جسد البقرة بالجهة اليمنى من المتلقي والتي اعتمد فيها الجهاز الهضمي من (البلعوم والمعدة والأمعاء .....), مستقراً (جسد البقرات) على الارض. فقد أظهر المنجز الخزفي منظومة بنائية مجردة فالثكل الدجرد جاء بقصدية واعية, فهو فعل محاكاتي تحولت فيه الحسية

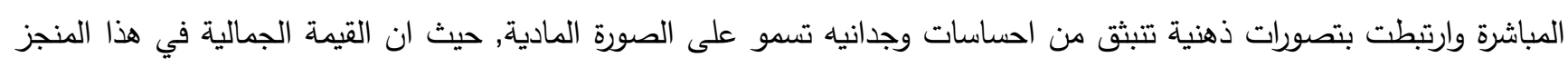

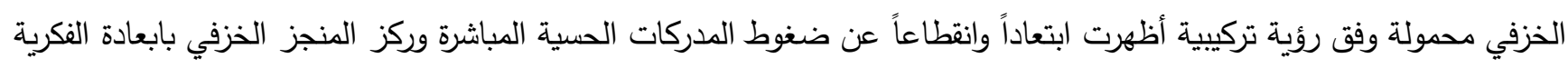
والبنائية هنا على استقصاء الجمال المجرد من خلال ما يظهره اللون الجوزي والبرتقالي والاصفر والاسود) والذي يغطي مجمل المنجز الخزفي والذي نفذ بأستخدام افران الوقود. وهنا نجد ان الهنجز الفني للخزاف (Muller - B-) قائم على التتاغم والتتاسق والانسجام اللوني محققاً احتفالاً ابداعياً بطريقة زخرفية (وجود البقع اللونيه التي غطت معظم السطح الخارجي للمنجز الخزفي) والتي جاءت كعاملاً اضافيا معيناً مجسداً لاكمال دلالة التهان المنجز الخزفي, فالالوان اعطت اضافات زخرفية وتكرار هذه الالوان ساعد على انجاز تتاظر ذكي لانية يخلق ملالًا للمتلقي بقدر ما يخلق احساساً بالثجن والامل بواسطة خلق تباينات في الحجم واللون والملمس مانحاً المنجز الخزفي قيمه جمالية عالية.

الفصل الرابع

(1) ريد, هربرت: النحت الحديث, ت: فخري خليل, مراجعة: جبر ابراهيم جبرا, دار المأمون للترجمة والنشر , بغداد, 1994, ص168. 
1. أن الخزف الاوربي المعاصر بأبعادة الفكرية والبنائية ليس بمعزل عن الطروحات الفكرية والفلسفية السائدة.

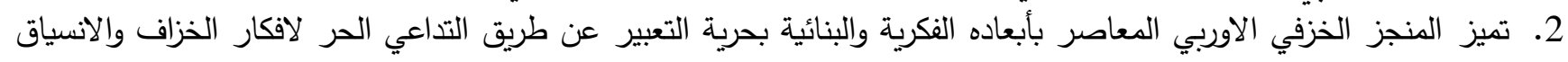
نحو حرية الفعل كما في عينه (1). 3. سقوط نظرية الانغلاق الجمالي والثكل الثئ المحدد في اجناس الفن التشكيلي, مما اعطى المنجز الخزفي نوعاً من الانشاء المفتوح

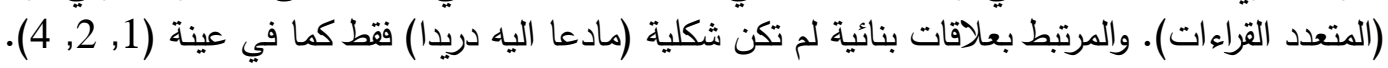

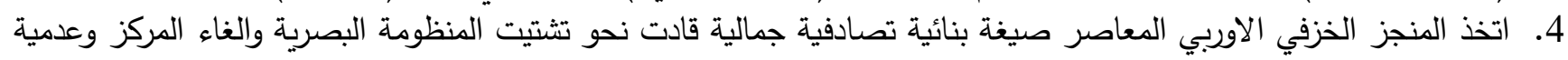

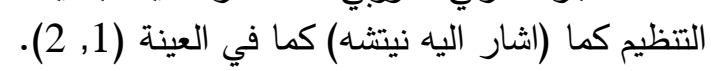

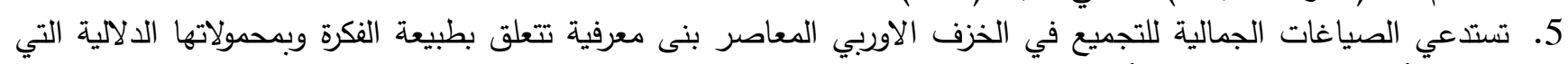

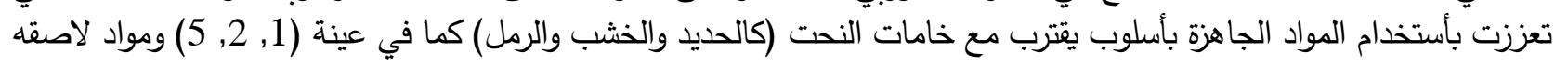

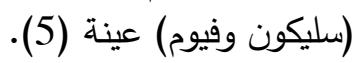
6. امتاز الخزف الاوربي المعاصر في في ابعادة الفكرية والبنائية بالتداخل بين اكثر من خطاب فني واحد كما في عينة (1, 2, 3, 4, 7. تركز فعل الخزاف في بنائية المنجز الخزفي الاوربي عبر تقنيات مختلفة لطرح لغة فنية جديدة لا مألوفه نفذت بأسلوب واقعي

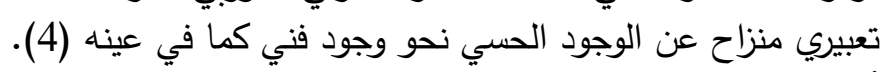

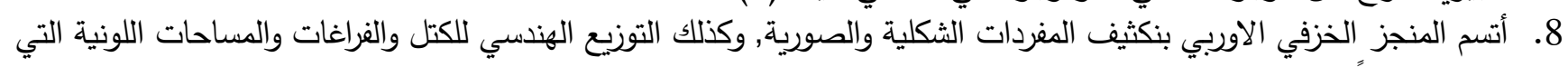

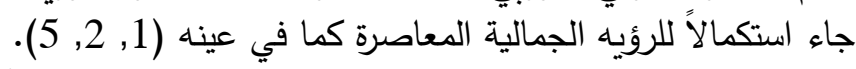

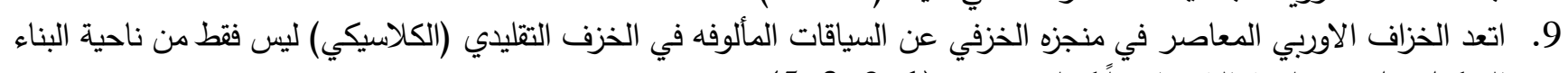

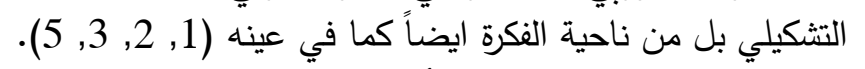

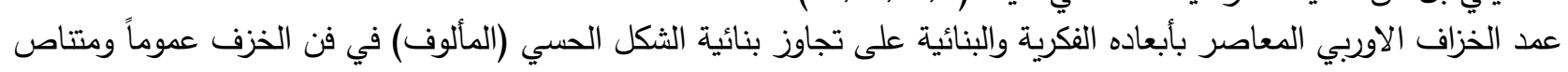

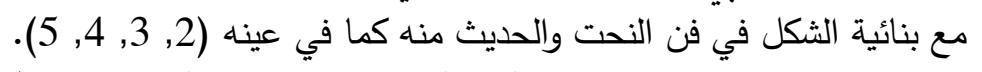

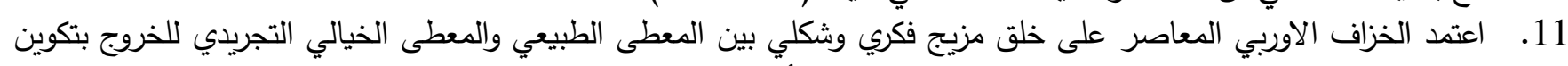

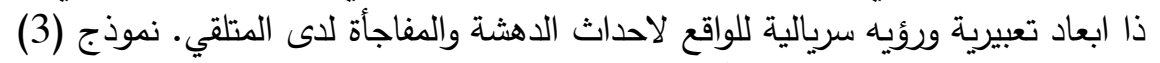

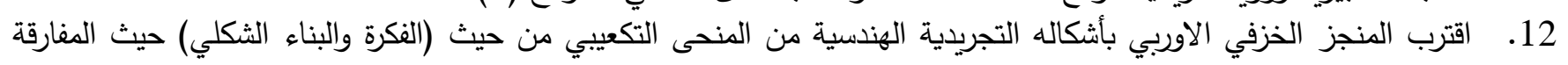

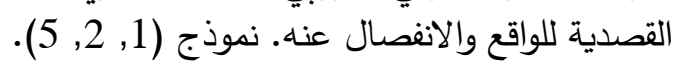

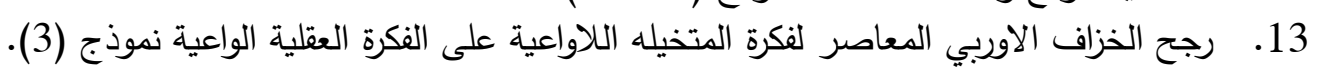

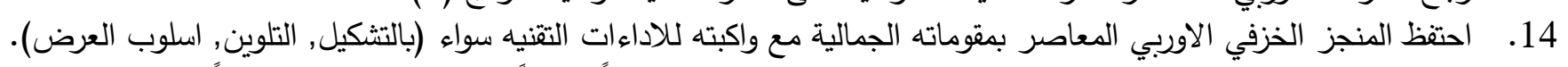

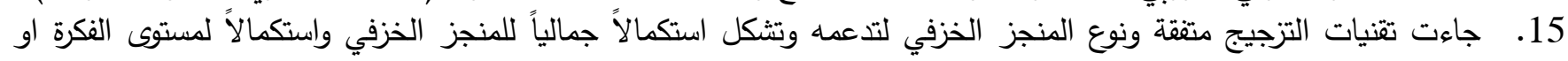

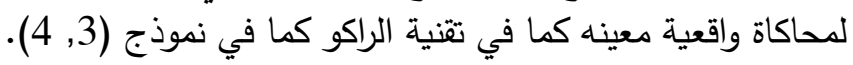
ثانياً: الاستنتاجات 1. اكدن نتاجات الخزاف الأفات الأوربي المعاصر بابعادها الفكرية والبنائية بما تحمله من اشكال تجريديه هندسية على فعل المغايرة

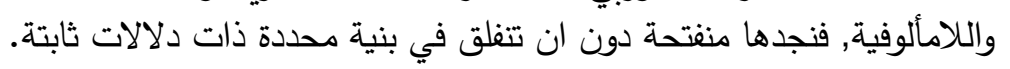

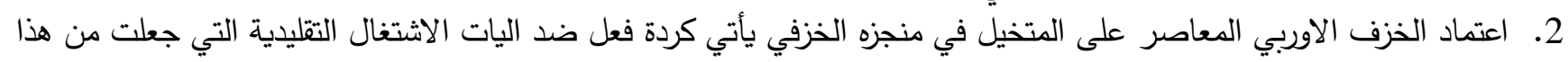
الفن حبيسا لاغراضه الوظيفية.

3. قدرة الخزاف الاوربي المعاصر على اختراق عالم الواقع وتصويره بحس جمالي انزياحي متخيل بعيداً عن محدودية ذلك الواقع.

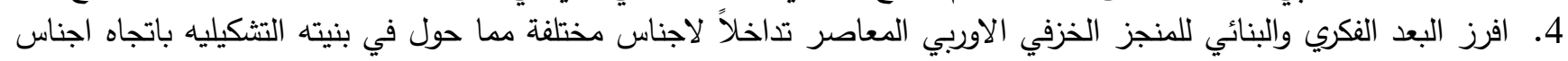
فنيه اخرى. 5. اثراء المنجز البصري الخزفي ببعدية الفكري والبنائي بايحاءات صياغيه جديدة يفترض من خلالها حاله من الوعي التجميعي في

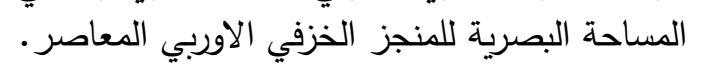

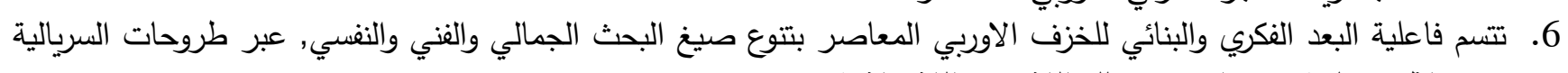
من خلال صياغة تصوراته عن عالم المئ اللاوعي والتلاعقلانية. 7. وصل الخزف الاوربي المعاصر الى مستوى التتوع التقني وعفوية الاختزال اللوني بأكاسيد التلوين والتي حققت فعلها في انتاج تقنية الراكو. ثالثاً: التوصيات:- 
1. د دعم وتثجيع البحوث والكتب والمجلات التي تغني مادة الخزف نقدياً وفنياً.

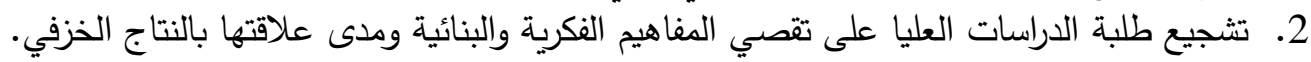
رابعاً: المقترحات:-

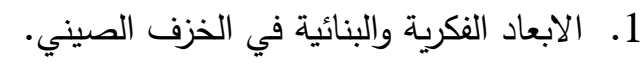
2. الابعاد الفكرية والبنائية وتمثلاتها في الخزف الفية الإنية الإيكي المعاصر . المصادر والمراجع

المصادر العربية

1. ابراهيم, زكريا: كانت والفلسفة النقدية, مكتبة مصر , القاهرة, ب.ت. التبة.

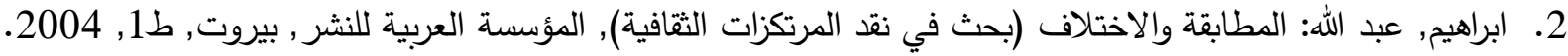

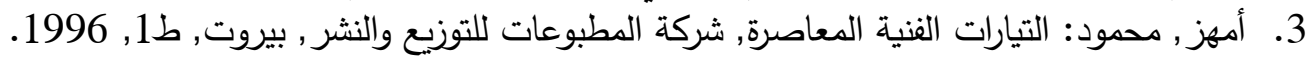
4. أمهز , محمود: التيارات الفنية المعاصرة, شركة المطبوعات للتوزيع والطباعة, بيروت, ط1, 1996.

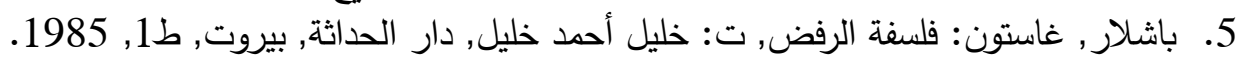

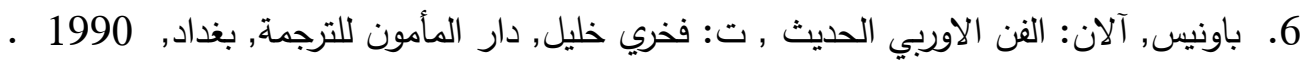
7.

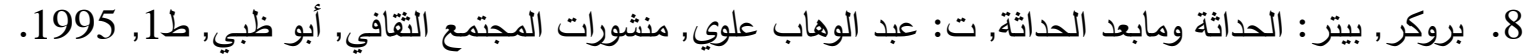

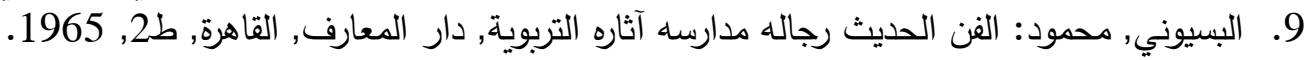

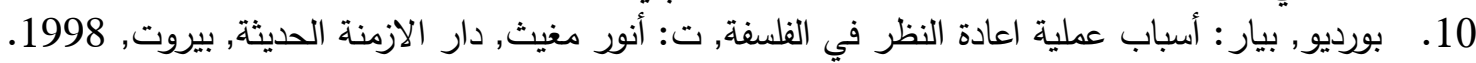
11. التريكي, فتحي: فلسفة الحداثة, مركز الانماء القومي, بيروت, 1092

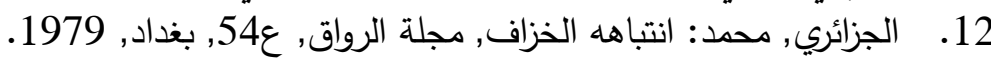

13. حسين, قاسم: فن النحت بين التقليد والحداثة, وزارة الثقافة, دار الثؤون الثقافية العامة, بغداد, ط1, 2013.

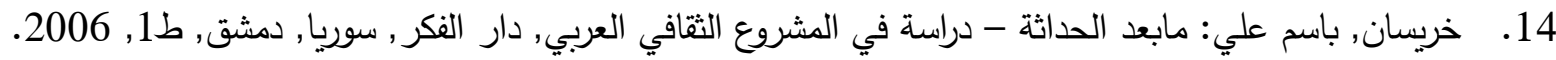

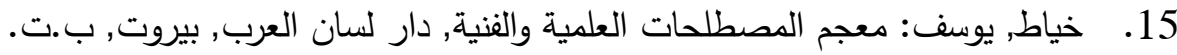
16. ديوي, جون: الفن خبرة, ت: زكريا ابراهيم, مراجعة: زكي نجيب دحمودة الفيان القاهرة, 1963.

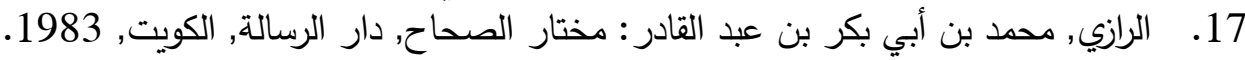

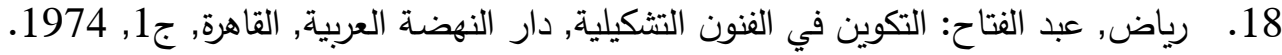

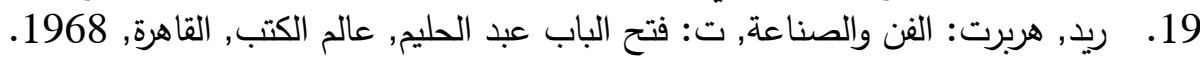
20. ريد, هربرت: النحت الحديث, ت: فخري خليل, مراجعة: جبر ابراهيم جبرا, دار المأمون للترجمة والنشر , بغداد, 1994.

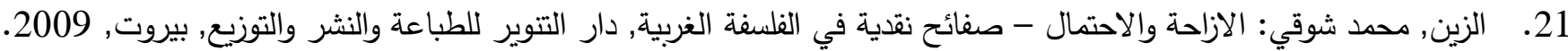

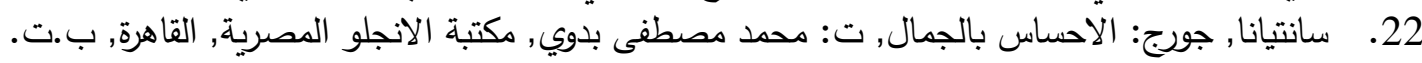
23. ستولنتز , جيروم: النقد الفني, ت: فئاد الاد زكريا, مطبعة علي الثمس, القاهرة, 1974.

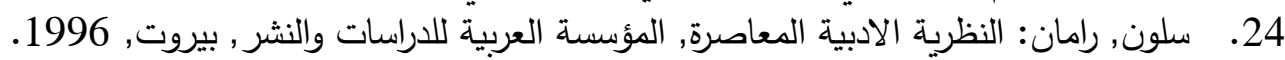
25. شاكر , عبد الحميد: عصر الصورة (السلبيات والايجابيات), سلسلة عالم المعرفة (311), الكويت, 2005.

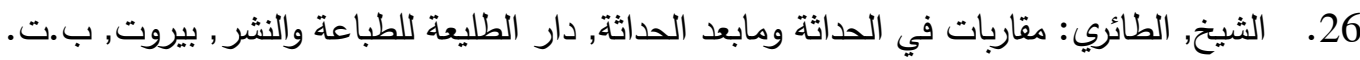
27. العالي, عبد السلام بنعبد: أسس الفكر الفلسفي المعاصر - مجاوزة الميتافيزيقيا, دار توبقال للنشر , الدار البيضاء, الدغرب, ط1, .1991

28. عبد حيدر , نجم وآخرون: دراسات في بنية الفن, دار مكتبة الرائد العلمية, عمان, الاردن, 2004.

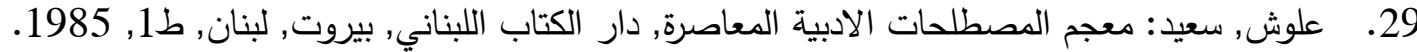

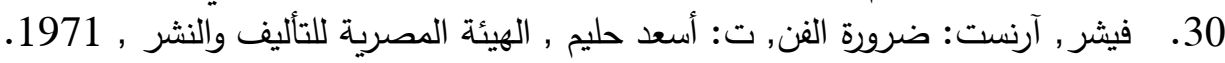

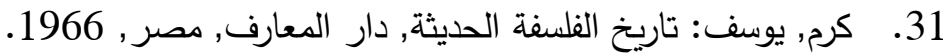

32. لجنة من العلماء والاكاديميين السوفيتين: الموسوعة الفلسفية المختصرة, مكتبة الانجلو المصرية, القاهرة, 1963. 33. مانغ, فيليب: جيل دولوز أو نسق المتعدد , ت: عبد العزيز بن عرفة , مركز الانماء الحضاري , مطبعة عكرمة ,دمشق , سوريا .2002,

34. مدكور , ابراهيم: المعجم الفلسفي, الهيئة العامة لثؤون المطابع الاميرية, القاهرة, 1977.

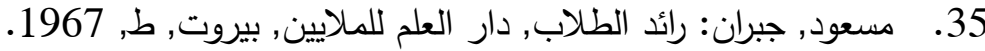

36. مصطفى, بدر الدين: حالة مابعد الحداثة الفلسفة والفن, الهيئة العامة لقصور الثقابنة الثقافة, القاهرة, ط1, 2013. 
38. البياتي, زينب كاظم صالح: التحائ التحولات الجمالية للتكوين الخزفي المعاصر , أطروحة دكتوراه غير منشورة, جامعة بغداد, كلية الفنون الجميلة, 2009.

39. البياتي, زينب كاظم صالح: التحولات الجمالية للتكوين الخزفي المعاصر , اطروحة دكتوراه غير منشورة, جامعة بغداد, 2009. 40. تراث, "أمين عباس : نظام الاختلاف في الخزف الفيات المعاصر , اطروحة دكتوراه غير منشورة, جامعة بابل, كلية الفنون الجميلة, 2010. 41. الخفاجي, أطياف علي نجم: اشكالية الهوية في الخزف العراقي المعاصر , اطروحة دكتوراه غير منشورة, جامعة بابل, كلية الفنون الجميلة, 2012.

42. الربيعي, نبراس احمد جاسم: انظمة اشكال الخزف العربي المعاصر , اطروحة دكتوراه غير منشورة, جامعة بغداد, كلية الفنون الجميلة, 2004.

43. الزبيدي, كاظم نوير كاظم: مفهوم الذاتي في الرسم الحديث, أطروحة دكتوراه, كلية الفنون الجميلة غير منشورة, جامعة بابل, 2002.

44. السعدي, ابتسام ناجي كاظم: التداولية في الخزف العراقي المعاصر , اطروحة دكتوراه غير منشورة, جامعة بابل, كلية الفنون الجميلة,

45. الطاهر , حيدر رؤوف سعيد: بنية المتخيل في الخزف المعاصر , اطروحة دكتوراه غير منشورة, جامعة بابل, كلية الفنون الجميلة, .2012

46. الطاهر , حيدر رؤوف سعيد: بنية المتخيل في الخزف المعاصر , اطروحة دكتوراه غير منشورة, جامعة بابل, كلية الفنون الجميلة, 2012

• غانم, فاروق عبد الكاظم: تتاسق التقنية والوعي الجمالي في اظهار الثكل الخزفي, اطروحة دكتوراه غير منشورة, جامعة بغداد, .47 كلية الفنون الجميلة, 2013. 48. الكناني, محمد: حدس الانجاز في البينية الابداعية في العلم والفن, اطروحة دكتوراه غير منشورة, كلية الفنون الجميلة, جامعة بغداد, .2004 49. الناصري, ثامر : الوحدة والتتوع في الخزف العراقي المعاصر , رسالة ماجستير منشورة, جامعة بغداد, كلية الفنون الجميلة, 2005. المصادر الأجنبية

50. Groh mamn, Will:klee, New York: harryn, abrams. Int.

51. Hornby, A.S.: Oxford Dictionary, Oxford University press, London, 1975. 